\title{
Three-Dimensional Sulfite Oxidase Bioanodes Based on Graphene Functionalized Carbon Paper for Sulfite/O2 Biofuel Cells
}

Tang, Jing; Werchmeister, Rebecka Maria Larsen; Preda, Loredana; Huang, Wei; Zheng, Zhiyong; Leimkuhler, Silke; Wollenberger, Ulla; Xiao, Xinxin; Engelbrekt, Christian; Ulstrup, Jens Total number of authors: 11

Published in:

ACS Catalysis

Link to article, DOI:

10.1021/acscatal.9b01715

Publication date:

2019

Document Version

Peer reviewed version

Link back to DTU Orbit

Citation (APA):

Tang, J., Werchmeister, R. M. L., Preda, L., Huang, W., Zheng, Z., Leimkuhler, S., Wollenberger, U., Xiao, X., Engelbrekt, C., Ulstrup, J., \& Zhang, J. (2019). Three-Dimensional Sulfite Oxidase Bioanodes Based on Graphene Functionalized Carbon Paper for Sulfite/O2 Biofuel Cells. ACS Catalysis, 9, 6543-6554. https://doi.org/10.1021/acscatal.9b01715

\section{General rights}

Copyright and moral rights for the publications made accessible in the public portal are retained by the authors and/or other copyright owners and it is a condition of accessing publications that users recognise and abide by the legal requirements associated with these rights.

- Users may download and print one copy of any publication from the public portal for the purpose of private study or research.

- You may not further distribute the material or use it for any profit-making activity or commercial gain

- You may freely distribute the URL identifying the publication in the public portal 


\section{Three-Dimensional Sulfite Oxidase Bioanodes Based on Graphene}

\section{Functionalized Carbon Paper for Sulfite/ $\mathrm{O}_{2}$ Biofuel Cells}

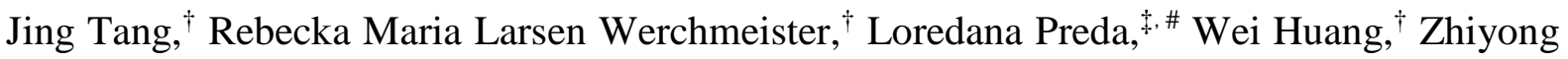

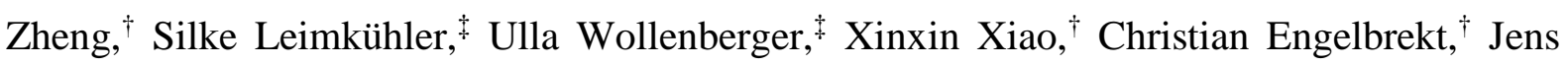
Ulstrup $^{\dagger}$ and Jingdong Zhang ${ }^{\dagger, *}$

† Department of Chemistry, Technical University of Denmark, 2800 Kongens Lyngby, Denmark

‡ Department of Molecular Enzymology, University of Potsdam, Potsdam-Golm 14476, Germany

\# on leave from Institute of Physical Chemistry of the Romanian Academy, 202 Spl. Independentei, 060021 Bucharest, Romania

* jz@kemi.dtu.dk 
ABSTRACT: We have developed a three-dimensional (3D) graphene electrode suitable for the immobilization of human sulfite oxidase (hSO), which catalyzes the electrochemical oxidation of sulfite via direct electron transfer (DET). The electrode is fabricated by dropcasting graphene-polyethylenimine (G-P) composites on carbon papers (CPs) pre-coated with graphene oxide (GO). The negatively charged hSO can adsorb electrostatically on the positively charged matrix (G-P) on CP coated with GO (CPG) electrodes with a proper orientation for accelerated DET. Notably, further electrochemical reduction of G-P on CPG electrodes leads to a 9-fold increase of the saturation catalytic current density $\left(\mathrm{j}_{\mathrm{m}}\right)$ for sulfite oxidation reaching $24.4 \pm 0.3 \mu \mathrm{A} \mathrm{cm} \mathrm{cm}^{-2}$, the highest value among reported DET-based $h S \mathrm{O}$ bioelectrodes. The increased electron transfer rate plays a dominating role in the enhancement of direct enzymatic current because of the improved electric contact of $h \mathrm{SO}$ with the electrode. The optimized $h S O$ bioelectrode shows significant catalytic rate $\left(\mathrm{k}_{\text {cat }}\right.$ : $\left.25.6 \pm 0.3 \mathrm{~s}^{-1}\right)$ and efficiency $\left(\mathrm{k}_{\mathrm{cat}} / \mathrm{K}_{\mathrm{m}}: 0.231 \pm 0.003 \mathrm{~s}^{-1} \mu \mathrm{M}^{-1}\right)$ compared to the reported hSO bioelectrodes. The assembly of the $h \mathrm{SO}$ bioanode and a commercial platinum biocathode allows the construction of sulfite/ $\mathrm{O}_{2}$ enzymatic biofuel cells (EBFCs) with flowing fuels. The optimized EBFC displays an open circuit voltage (OCV) of $0.64 \pm 0.01 \mathrm{~V}$, and a maximum power density of 61 $\pm 6 \mu \mathrm{W} \mathrm{cm}{ }^{-2}\left(122 \pm 12 \mathrm{~mW} \mathrm{~m}^{-3}\right)$ at $30^{\circ} \mathrm{C}$, which exceeds the best reported value by more than 6 times.

KEYWORDS: enzymatic biofuel cell, reduced graphene oxide, sulfite oxidase, carbon paper, direct electron transfer

\section{INTRODUCTION}

Electrochemical fuel cells (FCs) are energy conversion devices that harvest electricity from chemical energy stored in fuels. FCs have attracted intense attention as power generators for portable devices and automobiles. ${ }^{1-3}$ The development of efficient and durable catalysts for FCs has been a research hotspot for more than a decade. ${ }^{4,5}$ Noble metal catalysts such as 
platinum (Pt) show high efficiency, ${ }^{4,6}$ but are fraught with limited abundance and easy poisoning. In parallel, biological catalysts such as enzymes are promising candidates to be used for energy conversion, due to their sustainability, high catalytic activity and selectivity towards the substrates. ${ }^{7-11}$ FCs using enzymatic catalysts on the anode and/or cathode, known as enzymatic biofuel cells (EBFCs), can exploit a wide range of abundant biological fuels such as starch, ${ }^{12}$ glucose,${ }^{13,14}$ fructose ${ }^{15}$ and lactate, ${ }^{16,17}$ the oxidation of which is not sufficiently catalyzed by inorganic catalysts. ${ }^{13,} 18$ Moreover, EBFCs typically operate at ambient temperature and mild $\mathrm{pH},{ }^{19,} 20$ in contrast to established, strongly acidic/alkaline FCs.

Most EBFCs exploit small organic and biological molecules as fuels, but small inorganic molecules can also be utilized as fuels when electron communication between suitable enzymes and electrode surfaces is achieved. Human sulfite oxidase (hSO) catalyzes the oxidation of sulfite to sulfate (Equation 1), ${ }^{21,} 22$ which can be immobilized onto electrodes for bioanodes in sulfite/ $\mathrm{O}_{2}$ EBFCs. ${ }^{23}$ Oxidation of sulfite occurs at the molybdenum (Mo) containing co-factor, while a heme domain relays generated electrons from the Mo active site to the other natural redox partners, or to artificial electron acceptors. ${ }^{23-27}$ The electrons are transferred to an electrode either via direct heterogeneous electron transfer (DET) where the electrode is the direct redox acceptor or via mediated electron transfer (MET) with a redox mediator as the redox acceptor. ${ }^{28,29}$ DET of $h S O$ on electrode surfaces has been extensively studied. ${ }^{27,}{ }^{30} h S O$ is proposed to exist in two conformations switching between an "open" and a "closed" state. ${ }^{24,}$ 26, 27 In the “open” state, the heme group can react with an external electrode partner, but is unable to interact with the Mo co-factor. In the "closed" state, internal, intramolecular ET is triggered, while external ET is blocked. This suggests that the conformational change and enzyme orientation strongly affect ET efficiency between the Mo co-factor and the electrode surface in a "gated" overall enzymatic ET process. ${ }^{27}$

$$
\mathrm{SO}_{3}^{2-}+\mathrm{H}_{2} \mathrm{O} \stackrel{h \mathrm{SO}}{\longrightarrow} \mathrm{SO}_{4}^{2-}+2 \mathrm{H}^{+}+2 \mathrm{e}^{-}
$$


Positively charged electrode surface modifiers such as polyethylenimine (PEI) have been adapted to promote adsorption of $h S O$ (isoelectric point of $~ 5.5$ ) in a favorable orientation. ${ }^{30-}$ ${ }^{33}$ The immobilized $h S O$ on electrodes can achieve DET with a low onset potential of the sulfite oxidation (ca. -0.2 V vs. Ag/AgCl), ${ }^{23}$ holding promise for sulfite/ $\mathrm{O}_{2} \mathrm{EBFCs}$ with a high opencircuit-voltage (OCV). A sulfite/oxygen EBFC with OCV of $0.66 \mathrm{~V}$ constructed with a hSO /PEI/thiol/Au nanoparticle (AuNP)/Au bioanode and a bilirubin oxidase (BOx)/AuNP/Au based biocathode showing a maximum power density $\left(\mathrm{P}_{\max }\right)$ of $8 \mu \mathrm{W} \mathrm{cm}{ }^{-2}$ was in fact reported recently. $^{23}$

Design and preparation of electrode surfaces that can ensure that the stability and catalytic efficiency of the complex enzymes are retained or even improved on surface binding have been paramount in bioelectrochemical efforts. ${ }^{34}$ The introduction of nanomaterials offers a strategy to promote the performance of $h S \mathrm{SO}$ bioelectrodes. PEI-entrapped AuNPs covalently bound to a thiol-modified Au electrode have been successfully used for adsorption of $h S O$ with improved electrocatalytic performance ${ }^{31}$. PEI-capped CdS quantum dots (QDs) modified indium tin oxide (ITO) is also proved to be a suitable matrix for $h \mathrm{SO}$ immobilization undergoing efficient DET with negligible competition from dioxygen reduction. ${ }^{32}$ Graphene, a two-dimensional (2D) carbon nanomaterial, has been widely applied in bioelectrode fabrication for EBFCs and biosensors due to its outstanding properties such as high electrical conductivity, large surface area, and excellent mechanical strength. ${ }^{35-37}$ Reduced graphene oxides (RGOs) obtained from the reduction of graphene oxides (GOs) have some structural defects, but offer good biocompatibility due to the presence of residual hydroxyl and carbonyl groups. ${ }^{37}$ Both chemical and electrochemical reduction are efficient to obtain RGO from GO. ${ }^{38}$ Compared to chemical reduction, electrochemical reduction is much more environmentally friendly due to the elimination of utilization of hazardous reducing agents (e.g., hydrazine). The electrochemical reduction of GO is, in fact, an accumulative process. ${ }^{39}$ The inner GO 
layers in direct contact with a conducting electrode can be electrochemically reduced wherever accessible to the electrolyte, while the outer GOs can be gradually reduced, once insulating GOs inside are converted to conductive RGO. ${ }^{39}$ Three-dimensional (3D) graphene based electrodes such as graphene papers ${ }^{40}$ and graphene foams ${ }^{41}$ have emerged with considerable surface area for high-power-density FCs. This has prompted us to develop a 3D graphene substrate $^{42,43}$ specifically for $h \mathrm{SO}$ immobilization, which is expected to gain enhanced bioelectrochemical signals compared to other reported $h S O$ electrode materials due to a considerable surface area for the enzyme loading as well as local 3D environment to maintain the enzyme structure. ${ }^{32,44}$ Graphite electrodes have been used for the immobilization of $h S O .^{23}$, ${ }^{44,}{ }^{45}$ However, there are no reports on employing graphene to achieve DET between $h S O$ and the electrodes.

In the present work, 3D graphene-based electrodes using carbon papers (CPs) as supports coated with GO have been designed. The pre-treated CP covered with (CPG) with improved surface hydrophilicity allow easier penetration and modification of the graphene-PEI (G-P) mixture. The CPG electrode covered with G-P (CPG/G-P) is further electrochemically reduced (G-P/R) to increase electroactive surface area and decrease the charge transfer resistance. $h \mathrm{SO}$ is drop-casted onto the electrode (G-P/R), on the basis that the polycation PEI induces favorable orientation of hSO via electrostatic binding to facilitate DET. The importance of electrochemical reduction of the modified electrodes was confirmed by control experiments. G-P composition, as well as $\mathrm{pH}$ and ionic strength of the electrolytes were well optimized. Coupled with a Pt-based dioxygen reducing cathode, a two-compartment sulfite/ $\mathrm{O}_{2} \mathrm{EBFC}$ was further built and tested. The $h \mathrm{SO}$ EBFC runs well fed with a flow of $\mathrm{Na}_{2} \mathrm{SO}_{3}$ solution and dioxygen gas as fuels in the anodic and cathodic chambers, respectively. Notably, the $h S O$ EBFC with a flow setup has demonstrated a maximum power density that exceeds the 
performance of reported $h \mathrm{SO}$-based EBFCs by more than 6 times, offering perspectives as a biological power supply.

\section{EXPERIMENTAL SECTION}

Chemicals and Materials. Potassium permanganate $\left(\mathrm{KMnO}_{4}, \geq 99.9 \%\right)$ and potassium hexacyanoferrate(II) $\left(\mathrm{K}_{4}\left[\mathrm{Fe}(\mathrm{CN})_{6}\right] \cdot 3 \mathrm{H}_{2} \mathrm{O}, 99.0-102.0 \%\right)$ were from Merck (Germany), acetic acid $\left(\mathrm{CH}_{3} \mathrm{COOH}, \geq 99.8 \%\right)$ from Riedel-deHaën (Germany). Sodium sulfite $\left(\mathrm{Na}_{2} \mathrm{SO}_{3}, \geq\right.$ 98.0\%), cytochrome $c$ from bovine heart $(\geq 95 \%)$, hexaammineruthenium(III) chloride ([Ru( $\left.\left.\left.\mathrm{NH}_{3}\right)_{6}\right] \mathrm{Cl}_{3}, 98 \%\right)$, graphite powder $(<20 \mu \mathrm{m})$, tris(hydroxymethyl)aminomethane (Tris, $\left.\left(\mathrm{HOCH}_{2}\right)_{3} \mathrm{CNH}_{2}, \geq 99.9 \%\right)$, hydrogen peroxide $\left(\mathrm{H}_{2} \mathrm{O}_{2}, 34.5-36.5 \%\right)$, sulfuric acid $\left(\mathrm{H}_{2} \mathrm{SO}_{4}, 95\right.$ 97\%), hydrochloric acid ( $\mathrm{HCl}, 37 \%)$, potassium persulfate $\left(\mathrm{K}_{2} \mathrm{~S}_{2} \mathrm{O}_{8}, \geq 99 \%\right)$, phosphorous pentoxide $\left(\mathrm{P}_{2} \mathrm{O}_{5}, \geq 98 \%\right.$ ), branched polyethylenimine (PEI, molecule weight (MW) $=800$ or $25000 \mathrm{~g} \mathrm{~mol}^{-1}$ ), PEI solution (branched, 50\% wt $\%$ in $\mathrm{H}_{2} \mathrm{O}, \mathrm{MW}=1300$ or $750000 \mathrm{~g} \mathrm{~mol}^{-1}$ ), and the mediator $\mathrm{N}, \mathrm{N}, \mathrm{N}^{\prime}, \mathrm{N}^{\prime}$-tetramethyl-p-phenylenediamine (TMPD, 99\%) were from SigmaAldrich (USA). Branched PEI with a MW of $5000 \mathrm{~g} \mathrm{~mol}^{-1}$ (Lupasol G 100) was from BASF (Germany). hSO (from the Department of Molecular Enzymology, University of Potsdam, Germany) was expressed in Escherichia coli TP1000 cells containing plasmid pTG718 and purified following a previous protocol ${ }^{21}$. Ethanol (96\% vol.) was obtained from VWR Chemicals (USA). CP (product number EC-TP1-060, thickness of $190 \mu \mathrm{m}$ ) composed of carbon fibers with diameters of 6-8 $\mu \mathrm{m}$, Nafion membrane (perfluorinated ion exchange membrane, thickness $115 \mu \mathrm{m}$ ) and commercial platinum (Pt) cathodes (BC-H225-10F, the diameter of Pt nanoparticles: $5 \mathrm{~nm}$, loaded onto activated carbon: $1.0 \mathrm{mg} \mathrm{cm}^{-2}$ ) were purchased from Quintech (Germany). Glue gun (PKP 18 E) and hot melt adhesive (PolyVinyl Chloride, PVC) used to block CP were from BOSCH (Germany). All the solutions were prepared with 18.2 $\mathrm{M} \Omega \mathrm{cm}$ Millipore water. 
Synthesis of Graphene Based Nanomaterials (G-P). The detailed procedure of preparing GO by the modified Hummer's method ${ }^{4,46}$ is given in Supporting Information (SI). The G-P solution was produced by heating a solution containing $17.0 \mathrm{~mL}$ Millipore water, $2.0 \mathrm{~mL}$ GO solution $\left(1.0 \mathrm{mg} \mathrm{mL}^{-1}\right)$, and $1.0 \mathrm{~mL}$ PEI $\left(40 \mathrm{mg} \mathrm{mL}^{-1}\right)$ for $60 \mathrm{~min}$ at $95{ }^{\circ} \mathrm{C}$. The G-P mixtures were concentrated to $4.0 \mathrm{~mL}$ with a calculated concentration of $0.50 \mathrm{mg} \mathrm{mL}^{-1}$ graphene (RGO) and $10 \mathrm{mg} \mathrm{mL}^{-1} \mathrm{PEI}$ by centrifugation and kept at $4{ }^{\circ} \mathrm{C}$ for use. Unless otherwise specified, PEI with a MW of $25000 \mathrm{~g} \mathrm{~mol}^{-1}$ was used as the optimum for all electrode modification.

Fabrication of $\boldsymbol{h S O}$ Modified Bioelectrodes. Before modifications, the T-shape CP electrode with a working surface area $\left(0.50 \times 0.50 \mathrm{~cm}^{2}\right)$ was prepared with hot melt adhesive by a glue gun, Figure S1. The T-shape CP was sonicated in a GO solution $\left(1.0 \mathrm{mg} \mathrm{mL}^{-1}\right)$ for $120 \mathrm{~min}$ in an ice bath (denoted as CPG). This step increased the hydrophilicity of the CP by coating with GO, so that aqueous G-P mixture could permeate into the CPG electrodes.

hSO bioelectrodes (G-P/R/hSO) were fabricated by a three-step procedure, Scheme 1 . The recipe for the bioelectrode preparation is described as follows: $16 \mu \mathrm{L}$ G-P mixture was first drop-casted onto a $0.25 \mathrm{~cm}^{2}$ CPG electrode (labelled as G-P). After drying at room temperature, CPG/G-P was dipped ten times into deionized water to wash away any loosely bound nanomaterials. The CPG/G-P (or G-P electrode) was next reduced electrochemically by cyclic voltammetry (CV) with 10 cycles at $50 \mathrm{mV} \mathrm{s}^{-1}$ in a potential window between -1.1 and $0.2 \mathrm{~V}$ vs. Ag/AgCl (saturated $\mathrm{KCl}$ ) in $\mathrm{N}_{2}$ saturated $15 \mathrm{~mL}$ Tris-acetate buffer solution (100 mM, pH = 7.0), resulting in CPG/G-P/-1.1R simplified as G-P/R. Finally, $10 \mu \mathrm{L}$ of $10 \mu \mathrm{M}$ hSO in 0.5 mM pH 7.0 Tris-acetate buffer was drop-casted onto the moist G-P/R electrode. The resulting G-P/R/hSO electrode was dried in a petri dish for $\sim 2$ to $3 \mathrm{~h}$ and then stored in a high-humid atmosphere at $4{ }^{\circ} \mathrm{C}$. The humid atmosphere was achieved with a wet tissue covered in a petri dish (diameter: $5.5 \mathrm{~cm}$ ). Prior to electrochemical measurements, G-P/R/hSO electrodes were immersed ten times in $0.5 \mathrm{mM}$ pH 7.0 Tris-acetate buffer to remove loosely bound $h \mathrm{SO}$. To 
obtain the adsorption behavior of $h \mathrm{SO}$ on G-P/R electrodes. The amount of immobilized active $h \mathrm{SO}$ on the electrode is believed to be proportional to the catalytic response to the saturation concentration of substrate sulfite and the catalytic response of bioelectrodes obtained with different enzyme-incubation durations (from 5 to $180 \mathrm{~min}$ ) was recorded. Specifically, The GP/R electrode was incubated in $10 \mu \mathrm{L}$ of $10 \mu \mathrm{M} h \mathrm{hO}$ in $0.5 \mathrm{mM}$ pH 7.0 Tris-acetate buffer for $5,10,20,40,60,120$ or $180 \mathrm{~min}$ at $4{ }^{\circ} \mathrm{C}$ and then washed with $0.5 \mathrm{mM} \mathrm{pH} 7.0$ Tris-acetate buffer.

Control electrodes, including G-P/R/hSO using PEI with different MWs, PEI/R/hSO without RGO, and R/hSO without RGO and PEI, were prepared following the same procedure. G-P/R and G-P modified on CPG (CPG/G-P or G-P electrodes) without enzyme modification were also prepared. To optimize the electroreduction of G-P on CPG electrodes, the reduced electrodes with a potential window between $-0.9,-1.1,-1.3$ or -1.5 and $0.2 \mathrm{~V}$ vs. $\mathrm{Ag} / \mathrm{AgCl}$ (saturated $\mathrm{KCl}$ ) were obtained, labelled as G-P/-0.9R, G-P/-1.1R, G-P/-1.3R or G-P/-1.5R, respectively. Regarding the fabrication of $\mathrm{G}-\mathrm{P} / \mathrm{R} / \mathrm{hSO}$, the electrochemical reduction step of the modified CP was carried out either before the drop-cast of G-P (labelled R/G-P/hSO), or both before and after the drop-cast (labelled as R/G-P/R/hSO), Figure S2. G-P/hSO, hSO and G-P on CPG electrodes without electrochemical reduction were also prepared. 

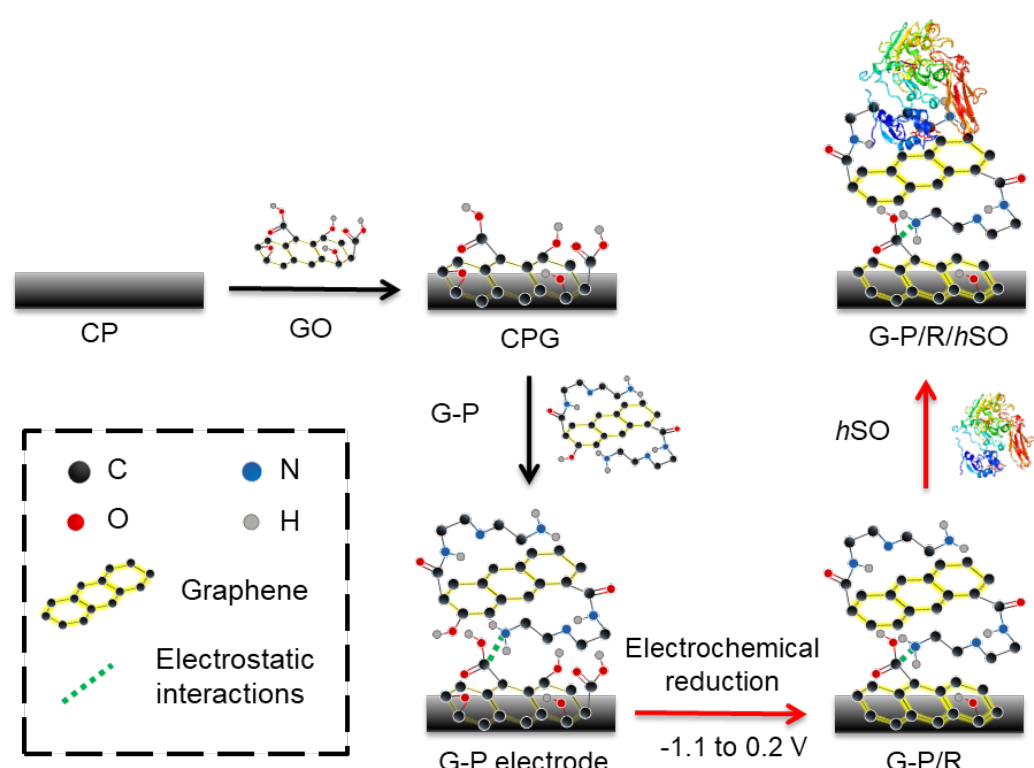

G-P/R/hSO
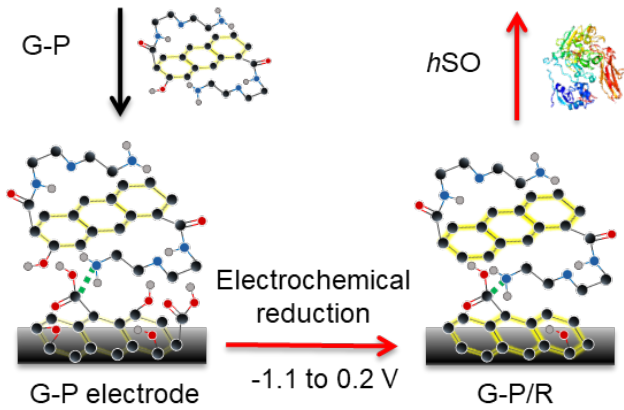

Scheme 1. Schematic illustration of three-step construction process of a G-P/R/hSO on a CPG electrode. Stronger yellowish color is used to show the graphene with high conductivity. $h S \mathrm{O}$, PDB:1SOX.

Characterizations. The morphology of the modified electrodes was characterized by scanning electron microscopy (SEM, FEI Quanta FEG 200 ESEM with an ETD detector, USA). The energy-dispersive X-ray spectroscopy (EDX) mapping was conducted to examine the distribution of elements. X-ray photoelectron spectroscopy (XPS) and Raman spectroscopic measurements were carried out using an ESCALABMKII X-ray photoelectron spectrometer (Thermo Scientific, USA) and a Raman spectrometer (Renishaw InVia, 633 nm Laser, UK), respectively. Atomic force microscopy (AFM) in a 5500 SPM system (Keysight Technologies, Santa Rosa CA, USA) controlled by the PicoView software in tapping mode was used to characterize the GO surface. UV-vis spectra of GO, GO+PEI and G-P nanomaterials dispersed in water were recorded by a UV-visible spectrophotometer (Agilent 8453, USA). The zeta potentials of GO and G-P nanomaterials with different molecule weights (MWs) of PEI were measured using a Zetasizer Nano (Malvern Instruments Ltd., UK).

Electrochemical Characterization of the Bioelectrodes. CV and chronoamperometry were carried out using a CHI 650B electrochemical workstation (CH Instruments, Inc., USA) or an 
Autolab PGSTAT12 (Eco Chemie, Netherlands), employing a three-electrode setup with a bioelectrode, a Pt wire, and $\mathrm{Ag} / \mathrm{AgCl}$ (saturated $\mathrm{KCl}$ ) as the working, counter, and reference electrode, respectively. All reported potentials are referred to the $\mathrm{Ag} / \mathrm{AgCl}$ (saturated $\mathrm{KCl}$ ) electrode. Unless otherwise stated, CV and chronoamperometry were recorded under stirring with a small magnet (10 mm diameter) at $20 \pm 2{ }^{\circ} \mathrm{C}$. The electrolyte, $15 \mathrm{~mL}$ Tris-acetate buffer solution $(750 \mathrm{mM}, \mathrm{pH}=8.4)$, was purged with nitrogen gas for 30 min to remove dissolved dioxygen prior to electrochemical tests. All electrochemical results were averages with calculated deviations (error bar in Figures) based on three replicates.

Electrochemical impedance spectroscopy (EIS) using an Autolab PGSTAT12 (Eco Chemie, Netherlands) with the NOVA 2.1 software was performed at $0.24 \mathrm{~V}$ vs. $\mathrm{Ag} / \mathrm{AgCl}$ in $100 \mathrm{mM}$ $\mathrm{KCl}$ containing $5.0 \mathrm{mM} \mathrm{K}_{4}\left[\mathrm{Fe}(\mathrm{CN})_{6}\right]$. The applied amplitude was $10 \mathrm{mV}$ and the frequency range 0.1 to $100 \mathrm{kHz}$. CV characterization of modified electrodes were also carried out with the scan rate $100 \mathrm{mV} \mathrm{s}^{-1}$ in oxygen-free $\mathrm{KCl}$ solution $(100 \mathrm{mM})$ containing $5.0 \mathrm{mM} \mathrm{K} \mathrm{K}_{4}\left[\mathrm{Fe}(\mathrm{CN})_{6}\right]$ or $\left[\mathrm{Ru}\left(\mathrm{NH}_{3}\right)_{6}\right] \mathrm{Cl}_{3}$ using the same Autolab.

Construction and Characterization of Sulfite/ $\mathbf{O}_{2}$ EBFCs. The square-shape G-P/R/hSO bioelectrode with a working surface area $\left(1.0 \times 1.0 \mathrm{~cm}^{2}\right)$ was used as the bioanode of an EBFC $\left(8.3 \times 8.3 \times 6.1 \mathrm{~cm}^{3}\right.$, Figure S3) together with a commercial Pt cathode separated by a Nafion membrane. Prior to the tests, the Nafion membrane was wetted with Millipore water for 3-4 h using a peristaltic pump at $2.0 \mathrm{~mL} \mathrm{~min}{ }^{-1}$. The fuel, i.e. $25 \mathrm{mM} \mathrm{Na}_{2} \mathrm{SO}_{3}$, for EBFC tests was supplied at $2.0 \mathrm{~mL} \mathrm{~min}{ }^{-1}$, where oxidizing saturation current under static conditions was obtained in presence of oxygen, Figure S4. A control FC with a G-P/R anode was also investigated. 


\section{RESULTS AND DISCUSSION}

Characterization of Electrode Materials. CP electrodes, consisting of carbon fibers (6-8 $\mu \mathrm{m}$ in diameter), possess large surface areas in three dimensions suitable for high enzyme loading. However, CP itself is hydrophobic, making it hard to disperse aqueous G-P mixtures and $h \mathrm{SO}$ solution uniformly on the surface. The CP was therefore first sonicated in a GO solution to improve its hydrophilicity by coating with GO. SEM confirms that small flakes, regarded as GO sheets characterized by AFM (Figure S5a), appear on the carbon fibers of CPG (Figure 1a and S6), in contrast to bare CP (Figure 1a inset). This indicates that hydrophilic GO is deposited on the carbon fibers via $\pi-\pi$ interactions ${ }^{47}$ without changing the original 3D structure of the CPs. Larger thin flakes (added as G-P sheets) can, therefore, be uniformly immobilized on CPG, Figure 1b. After electrochemical reduction, the coated nanomaterials aggregate, Figure 1c, because the reduced GOs tend to restack by $\pi-\pi$ interactions. ${ }^{39}$ The immobilization of $h \mathrm{SO}$ appears to result in further aggregation, due to the electrostatic interactions between negatively charged protein and positively charged G-P nanomaterials, Figure 1d. As observed by EDS mapping, the distribution of nitrogen becomes non-uniform after hSO immobilization, implying that the observed aggregates contain PEI, Figure S7. 

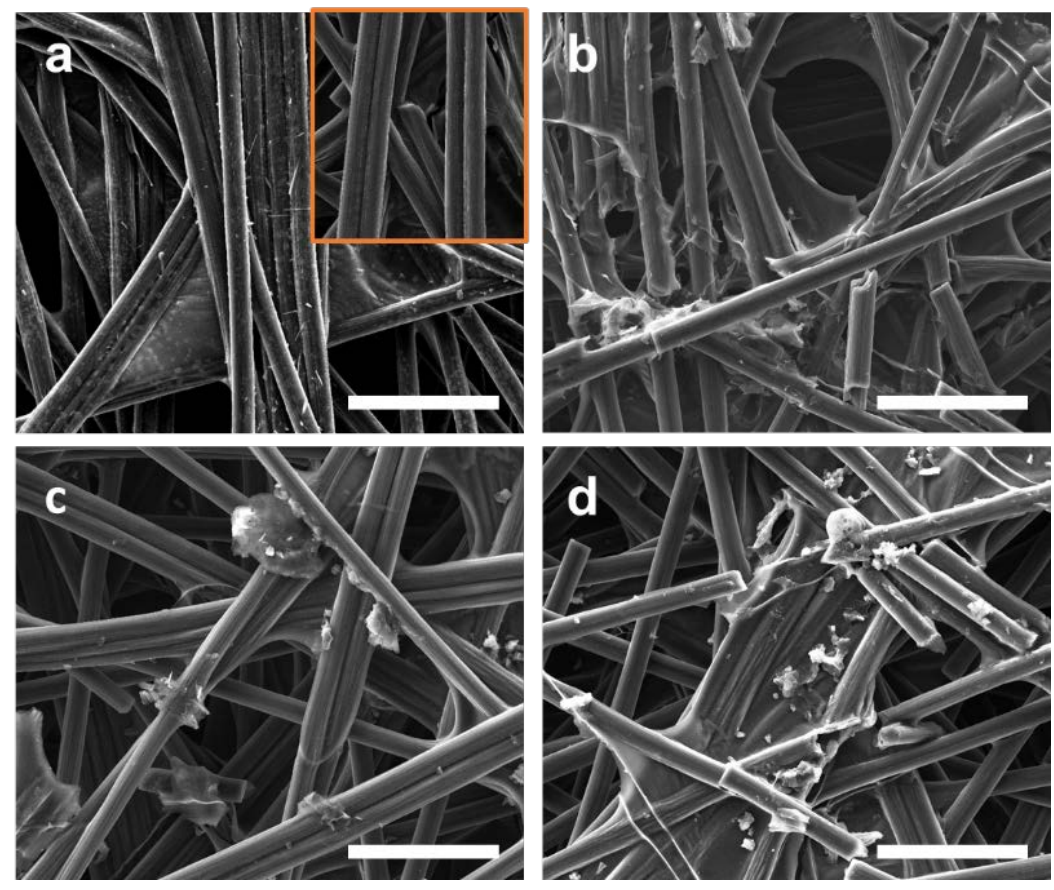

Figure 1. SEM images of (a) CPG (inset: bare CP), (b) CPG/G-P, (c) CPG/G-P/R and (d) G$\mathrm{P} / \mathrm{R} / \mathrm{hSO}$ on CPG electrodes; scale bar: $50 \mu \mathrm{m}$.

XPS was used to examine the surface chemical composition, especially the carbon bonding states of the CP, CPG, CPG/G-P and CPG/G-P/R electrodes. The narrow spectra for C1s are well fitted by peaks at $284.5 \pm 0.1,285.0 \pm 0.1,285.9 \pm 0.1,286.6 \pm 0.1,287.4 \pm 0.1$ and 288.6 $\pm 0.1 \mathrm{eV}$, assigned to carbon atoms in C-sp ${ }^{2}, \mathrm{C}-\mathrm{sp}^{3}, \mathrm{C}-\mathrm{N}, \mathrm{C}-\mathrm{O}, \mathrm{C}=\mathrm{O}$ and $\mathrm{COOH}, 4,35,40,48$ respectively, Figure S5b and Figure 2. The percent contribution of each carbon species, namely the relative peak area of each fitted component to the total carbon species, and values of the binding energy are summarized in Table S1. After coating of the CP by GOs, the relative amount of oxygenated carbon species, i.e., $\mathrm{C}-\mathrm{O}, \mathrm{C}=\mathrm{O}$ and $\mathrm{COOH}$, drastically increases from 4.0, 2.7 and 4.0\% (of all carbon species) for CP to 20.7, 16.7 and 6.4\% for CPG, respectively, Table S1. Such large amounts of oxygenated species originate from the GO film formed on the CP electrode. ${ }^{48}$ The unexpected small amount of C-N species (Table S1) is likely from the inevitable impurities in CP. As expected, the presence of G-P nanomaterials increases the peak intensity of C-N 14-fold (from 1.6 for CPG to 22.9\% for CPG/G-P), indicating successful functionalization of CPG with G-P. After electrochemical reduction of the CPG/G-P electrode, 
only a 5.1\% decrease for total oxygenated species, i.e. $\mathrm{C}-\mathrm{O}, \mathrm{C}=\mathrm{O}$ and $\mathrm{COOH}$, was observed, Table S1. This might be because the electrochemical reduction step mainly affects GO coated on the CP by sonication. This GO is covered by the G-P nanocomposite, which dominates the XPS spectra, and is not affected by electroreduction. This is confirmed by that electroreduction of CPG (CPG/R) leads to a $28.2 \%$ loss of total oxygenated species compared with the CPG electrode, Figure S5b, and Table S1.

Raman spectra (Figure 2d) show the fingerprint signals of graphene. The D band is assigned to the disordered or defect in graphene or graphite materials, while the G band is associated with the vibration of $\mathrm{sp}^{2}$ hybridized C-C bonds. ${ }^{49}$ Figure $2 \mathrm{~d}$ shows that the $\mathrm{I}_{\mathrm{D}} / \mathrm{I}_{\mathrm{G}}$ ratio of $\mathrm{CPG} / \mathrm{G}-\mathrm{P}$ (1.02) is higher than that of CPG (0.58), suggesting that the G-P nanomaterial coating on CPG shows a more highly disordered structure. The highest $\mathrm{I}_{\mathrm{D}} / \mathrm{I}_{\mathrm{G}}$ ratio (1.14) for CPG/G-P/R suggests the presence of a higher content of carbonaceous defects and disordered graphitized structure, resulting from the reduction of GOs to graphene sheets and their interactions with PEI. ${ }^{50,51}$ It is thus confirmed with XPS and Raman spectroscopy that electrochemical treatment further increases the degree of GO reduction to graphene. 

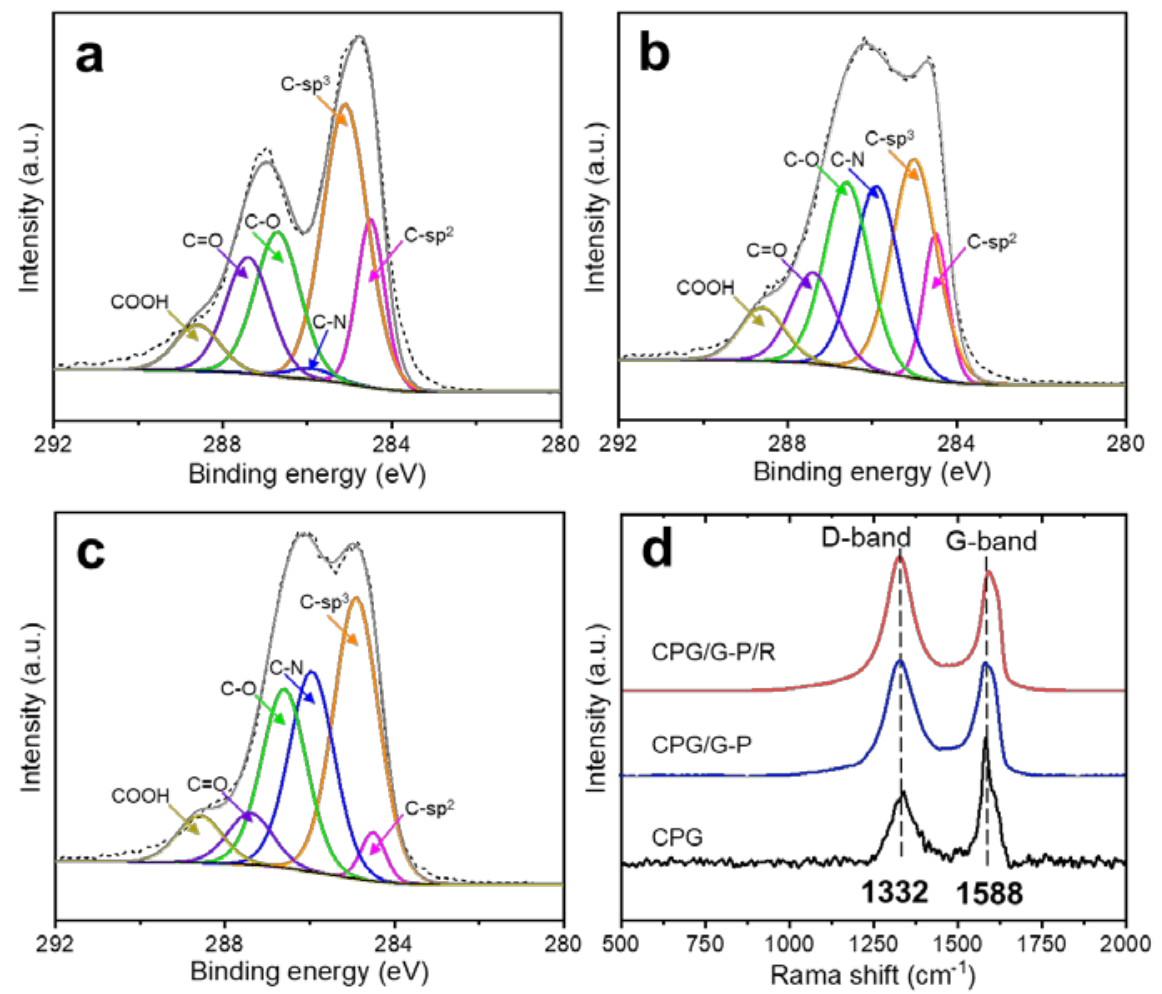

Figure 2. C1s XPS spectra of (a) CPG, (b) CPG/G-P and (c) CPG/G-P/R. (d) Raman spectra of various electrodes. Black dot-curves in (a), (b) and (c) are experimental data.

The GO nanomaterials show a negative zeta potential $(-7.8 \pm 0.2 \mathrm{mV})$ in $750 \mathrm{mM}$ Tris-acetate buffer solution (pH 8.4) because of the presence of oxygenated species, Table S2. Introduction of PEI with higher MWs increases the positive electrostatic charge of G-P nanomaterials except for G-P with the lowest MW (800 $\mathrm{g} \mathrm{mol}^{-1}$ ), which might be due to the weaker dispersion ability of the short polymer chains for the reduced GO produced.

Electrochemical Characterization of Modified Electrodes. To examine the influence of the electrode modifications, especially electrochemical reduction of CPG/G-P, on the electrochemical properties of the electrodes, we carried out EIS (Figure 3a) and CV studies (Figure 3b and Table S3) on $100 \mathrm{mM} \mathrm{KCl}$ containing $5.0 \mathrm{mM} \mathrm{K} 4\left[\mathrm{Fe}(\mathrm{CN})_{6}\right]$. The Nyquist plots are shown in Figure 3a. The equivalent circuit depicted in Figure 3a (inset) was fitted to the impedance spectra. As a certain degree of electrode roughness and inhomogeneity is evidenced according to SEM images, the use of a constant phase element (CPE) instead of a capacitance is appropriate. ${ }^{52-54}$ Table S4 shows that CPG gives the highest charge transfer resistance $\left(\mathrm{R}_{\mathrm{ct}}\right)$ 
of $181 \Omega$ among all the non-enzymatic electrodes, consistent with the CV curves which display the largest peak-peak separation $\Delta \mathrm{Ep}$ of $325 \mathrm{mV}$, and the smallest anodic peak current of 1.53 $\mathrm{mA} \mathrm{cm}^{-2}$ for the CPG electrode (black curve Figure $3 \mathrm{~b}$ and Table S3). This is due to the electrostatic repulsion between the negatively charged $\mathrm{CPG}$ surface and $\left[\mathrm{Fe}(\mathrm{CN})_{6}\right]^{3-/ 4-}$, as well as the relatively low conductivity of GO. After coating of G-P on the CPG electrode, it is not surprising to observe a significant decrease of $R_{\mathrm{ct}}$ to $30.5 \Omega$. Additionally, an increased peak current $\left(3.41 \mathrm{~mA} \mathrm{~cm}^{-2}\right)$, and a narrowed peak-peak separation $\Delta \mathrm{Ep}(173 \mathrm{mV})$ were observed for $\left[\mathrm{Fe}(\mathrm{CN})_{6}\right]^{4-}$ (Figure 3b), but a larger $\Delta \mathrm{Ep}$ (from 185 to $205 \mathrm{mV}$ ) for $\left[\mathrm{Ru}\left(\mathrm{NH}_{3}\right)_{6}\right]^{3+}$ (Figure S8 and Table S3). This is due to the addition of the polycationic PEI layer that alters the surface charge from negative to positive, consistent with the observation from the zeta potential measurements. The G-P on the CPG electrode is then electrochemically reduced with increasing potential windows, i.e., -0.9 to $0.2 \mathrm{~V},-1.1$ to $0.2 \mathrm{~V},-1.3$ to $0.2 \mathrm{~V}$ and -1.5 to $0.2 \mathrm{~V}$. $\mathrm{R}_{\mathrm{ct}}$ further drops from $19.4,16.7,15.8$ to $12.6 \Omega$ with the more negative potentials for reduction of GO, Figure S9a and Table S4. On the other hand, larger electroreduction potential windows with more negative potentials result in smaller capacitive currents, Figure S10a, as indicated by the electrochemically active surface area (ECSA). The ECSAs of these reduced electrodes decrease from $20 \pm 1,18.6 \pm 0.7,15.6 \pm 0.6$ to $15 \pm 1 \mathrm{~cm}^{2}$ for the potential window -0.9 to 0.2 $\mathrm{V},-1.1$ to $0.2 \mathrm{~V},-1.3$ to $0.2 \mathrm{~V}$ and -1.5 to $0.2 \mathrm{~V}$, respectively, Table S5. Since electrodes with lower $\mathrm{R}_{\mathrm{ct}}$ and higher ECSA are usually more promising for bioelectrode fabrication, the potential window between -1.1 to $0.2 \mathrm{~V}$ was chosen for reduction of G-P and GO nanomaterials on the electrodes, Table S6, and the electrode CPG/G-P/-1.1R elsewhere denoted as G-P/R elsewhere. Upon electroreduction, both $\left[\mathrm{Fe}(\mathrm{CN})_{6}\right]^{4-}$ and $\left[\mathrm{Ru}\left(\mathrm{NH}_{3}\right)_{6}\right]^{3+}$ give a reduced $\Delta \mathrm{Ep}$ due to the decreased electron transfer resistance, Table S3. After introduction of hSO on the G$\mathrm{P} / \mathrm{R} / h S \mathrm{O}, \mathrm{R}_{\mathrm{ct}}$ increases dramatically to $258 \Omega$, reflecting that $h \mathrm{SO}$ is well immobilized on the 
electrode surface in accordance with the capacity measurements and reports on other enzyme electrodes. ${ }^{55}$

The oxidation of sulfite on G-P/R/hSO electrodes was found to start at about $-0.20 \mathrm{~V}$ vs. $\mathrm{Ag} / \mathrm{AgCl}$, in good agreement with previous reports. ${ }^{23,32}$ This potential is notably lower than for the G-P/R electrode without $h \mathrm{SO}(\sim 0.02 \mathrm{~V}$ vs. Ag/AgCl), Figure 3c. This indicates that the immobilized $h \mathrm{SO}$ shows catalytic activity towards the oxidation of $\mathrm{Na}_{2} \mathrm{SO}_{3}$, rather than the support electrode itself. The G-P/R/hSO bioelectrode shows 5.6-fold higher catalytic and 1.5fold higher capacitive current compared to that of R/hSO (Figure 3c and Table S5). The G-P modification therefore clearly increases the surface area for the amount of $h S O$ capable of DET, which is supported by the higher estimated ECSA, increased from $14 \pm 1 \mathrm{~cm}^{2}$ for R/hSO to 36 $\pm 1 \mathrm{~cm}^{2}$ for G-P/R/hSO, Table S5 and Figure S10b. Similar phenomena were observed for G$\mathrm{P} / \mathrm{hSO}$ without electroreduction, Figure S11. Notably, the G-P/R/hSO bioelectrode exhibits both 9-fold higher oxidation catalytic of G-P/hSO bioelectrodes without electrochemical reduction, Figure 3d. This also accords with the 9-fold increased capacitive current and ECSA for G-P/R/hSO $\left(36 \pm 1 \mathrm{~cm}^{2}\right)$ compared to G-P/hSO $\left(3.6 \pm 0.2 \mathrm{~cm}^{2}\right)$ without the irreversible electrochemical reduction of GO on the electrodes, Figure S12 and Table S5. The promoted electrochemical properties and catalytic activity are ascribed to the improved conductivity of modified electrodes via electroreduction of GO on electrodes and thus the increased ECSA. 

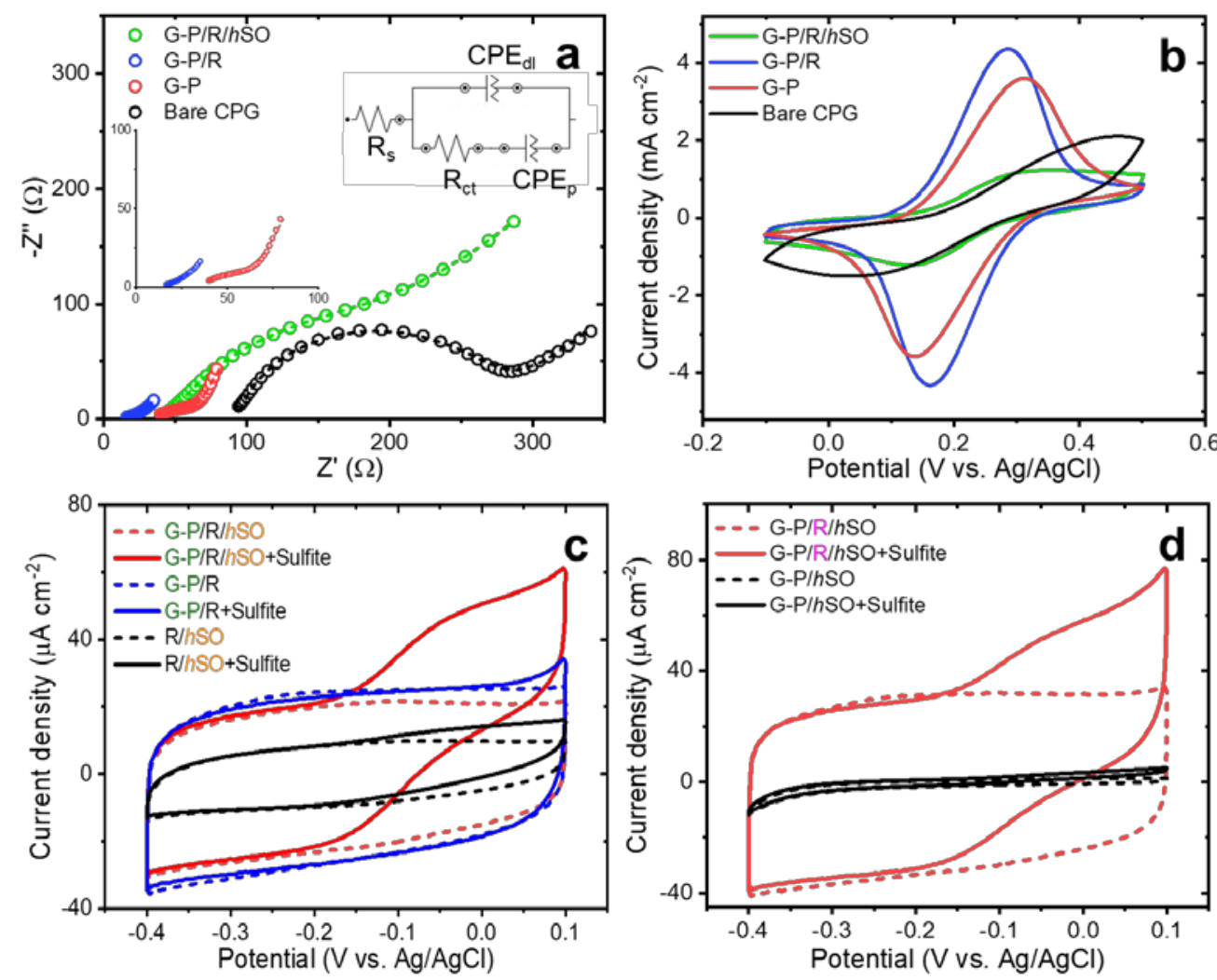

Figure 3. (a) EIS and (b) CVs at $100 \mathrm{mV} \mathrm{s}^{-1}$ of bare CPG, G-P, G-P/R and G-P/R/hSO electrodes recorded for $100 \mathrm{mM}$ oxygen-free $\mathrm{KCl}$ with $5.0 \mathrm{mM} \mathrm{K} 4\left[\mathrm{Fe}(\mathrm{CN})_{6}\right]$. Inset at the right corner in (a): the equivalent circuit used to fit impedance data; $\mathrm{R}_{\mathrm{s}}$ : electrolyte solution resistance, $\mathrm{R}_{\mathrm{ct}}$ : interfacial electron transfer resistance, $\mathrm{CPE}_{\mathrm{dl}}$ and $\mathrm{CPE}_{\mathrm{p}}$ : constant phase element of the electrode double layer and polarization, respectively. Inset at the left side in (a): the magnified EIS of G-P and G-P/R electrodes. (c) CVs of the G-P/R/hSO, G-P/R, and R/hSO electrodes and (d) G-P/R/hSO and G-P/hSO bioelectrodes in oxygen-free Tris-acetate buffer solutions (750 mM, pH 8.4) without (dashed) and with (solid) $1.0 \mathrm{mM} \mathrm{Na} \mathrm{SO}_{3}$; scan rate: 5 $\mathrm{mV} \mathrm{s}^{-1}$.

Effects of Electroreduction on Bioelectrocatalysis. To further understand how the electroreduction treatment remarkably promotes the heterogeneous bioelectrocatalysis, the activity of all washing buffer solution and the washed bioelectrodes has been assayed, Figure S13. It seems that the immobilization of $h S O$ on aggregated substrate does not significantly change the activity, since the total relative enzyme activities (immobilized and detached portion) of G-P/R/hSO and G-P/hSO are $86 \pm 5$ and $97 \pm 3 \%$ of the drop-casted enzyme, respectively, Table S7. The slightly lower activity for G-P/R/hSO is probably due to the inactivity inside the nanomaterials or the reduced accessibility of bound enzyme. 
The enzyme activity in the solutions of ten successive washing steps is shown in the Figure S14a. It shows that the washing process can remove loosely bound enzyme from the bioelectrodes. Compared with the activity of all washing solutions for the bioelectrode without electroreduction $(\mathrm{G}-\mathrm{P} / \mathrm{hSO}, 0.048 \pm 0.002 \mathrm{U})$, the washing solutions for the G-P/R/hSO electrode exhibit a $42 \%$ lower value (0.028 $\pm 0.001 \mathrm{U})$, Table S7. This implies that the G-P/R electrode substrate is more suitable for $h \mathrm{SO}$ immobilization. The washed G-P/R/hSO electrode (55 $\pm 4 \%$ of the total enzyme) shows $11 \%$ higher total enzymatic activity compared to the washed G-P/hSO (44 $\pm 1 \%$ ), Figure S14b and Table S7. This indicates that G-P/R/hSO carries only $11 \%$ more active $h S O$ than the G-P/hSO, even though the G-P/R modified electrode exhibits 9-fold higher estimated ECSA than the G-P modified electrode. Figure 3d shows that the G-P/R/hSO bioelectrode shows 9-fold higher electrocatalytic oxidation current compared to G-P/hSO. This significantly enhanced DET response of G-P/R/hSO therefore proves that the increased interfacial electron transfer plays the decisive role. Furthermore, the estimated $\mathrm{R}_{\mathrm{ct}}(258 \Omega)$ of $\mathrm{G}-\mathrm{P} / \mathrm{R} / \mathrm{hSO}$ is smaller than the value $(300 \Omega)$ of the bioelectrode without additional electrochemical reduction, a complementary indication of the enhance contact between the electrode and electroactive compounds, Figure S9b. The reduction in $\mathrm{R}_{\mathrm{ct}}$ might be caused by slight reduction of the amount of oxygenated species and thus less negative charge on the electrode surface.

Optimization of Bioelectrodes. The oxidation current for the G-P/R/hSO electrode on increasing $\mathrm{Na}_{2} \mathrm{SO}_{3}$ concentrations follows Michaelis-Menten kinetics and reaches saturation at $1.0 \mathrm{mM}$, Figure 4a. Based on the estimated surface concentration of $h \mathrm{SO}$ (Figure S15), the saturation values of the catalytic current density $\mathrm{j}_{\mathrm{m}}$, turnover number $\mathrm{k}_{\mathrm{cat}}$, and catalytic efficiency $\mathrm{k}_{\mathrm{cat}} / \mathrm{K}_{\mathrm{m}}$ are summarized in Table S8 and S9. Optimizations of (1) the electroreduction procedure, (2) graphene concentration in the G-P mixture, (3) effects of PEI with different 
MWs, (4) enzyme incubation durations, and (5) media (pH and ionic strength) were further investigated.

The catalytic performance of $h S O$ electrodes with three different reduction procedures, i.e., R/G-P/hSO, G-P/R/hSO, or R/G-P/R/hSO electrodes (the electrochemical reduction conducted before, after, or both before and after the drop-casting of G-P nanomaterials) is compared in Figure $4 \mathrm{~b}$. $\mathrm{j}_{\mathrm{m}}$ on $\mathrm{G}-\mathrm{P} / \mathrm{R} / \mathrm{hSO}\left(24.4 \pm 0.3 \mu \mathrm{A} \mathrm{cm} \mathrm{cm}^{-2}\right)$ is seven times higher than on $\mathrm{R} / \mathrm{G}-\mathrm{P} / \mathrm{hSO}$ (3.42 $\left.\pm 0.04 \mu \mathrm{A} \mathrm{cm}^{-2}\right)$, and twice higher than on R/G-P/R/hSO $\left(12.7 \pm 0.2 \mu \mathrm{A} \mathrm{cm}{ }^{-2}\right)$, Table S8. The highest $\mathrm{k}_{\mathrm{cat}}\left(25.6 \pm 0.3 \mathrm{~s}^{-1}\right)$ and $\mathrm{k}_{\mathrm{cat}} / \mathrm{K}_{\mathrm{m}}\left(0.231 \pm 0.003 \mathrm{~s}^{-1} \mu \mathrm{M}^{-1}\right)$ are also achieved for G$\mathrm{P} / \mathrm{R} / h$ SO. As can be seen from Table $1, \mathrm{G}-\mathrm{P} / \mathrm{R} / \mathrm{hSO}$ displays a $\mathrm{k}_{\text {cat }}\left(25.6 \pm 0.3 \mathrm{~s}^{-1}\right)$ comparable to those on AuNPs, ${ }^{55}$ and to the best of our knowledge, the highest $\mathrm{j}_{\mathrm{m}}$ reported $(24.4 \pm 0.3 \mu \mathrm{A}$ $\left.\mathrm{cm}^{-2}\right) .{ }^{23,27,32,44}$ This is attributed to the high specific surface area of the RGO based 3Delectrode, enabling high enzyme loading. The electrochemical reduction of modified CPs before the drop-cast of G-P, however, might decrease the hydrophilic level of the CPG electrodes, leading to weaker interaction between the G-P and the electrode surface, and thus reduced electroactive surface area. This is supported by the calculated ECSAs for R/G-P/hSO and $\mathrm{R} / \mathrm{G}-\mathrm{P} / \mathrm{R} / \mathrm{hSO}$, which are only $28 \%$ and $38 \%$ of the value of $\mathrm{G}-\mathrm{P} / \mathrm{R} / \mathrm{hSO}$, respectively, Table S5.

Table 1. Comparison of catalytic performance $\left(\mathrm{j}_{\mathrm{m}}\right.$ and $\left.\mathrm{k}_{\mathrm{cat}}\right)$ of $h S \mathrm{~S}$ immobilized on different modified electrodes with DET reported in literature.

\begin{tabular}{ccccccc}
\hline hSO on modified surface & Buffer & $\mathrm{pH}$ & $\begin{array}{c}\text { Ionic } \\
\text { strength } \\
(\mathrm{mM})\end{array}$ & $\mathrm{j}_{\mathrm{m}}\left(\mu \mathrm{A} \mathrm{cm}^{-2}\right)$ & $\mathrm{k}_{\text {cat }}\left(\mathrm{s}^{-1}\right)$ & Refs. \\
\hline CPG/G-P/R & Tris-acetate & 8.4 & 750 & $24.4 \pm 0.3$ & $25.6 \pm 0.3$ & This work \\
Au/AuNP/PEI & Tris & 8.4 & 750 & $0.37 \pm 0.02$ & - & 31 \\
ITO/CdS & Tris-acetate & 8.4 & 750 & $1.0 \pm 0.1$ & 27.1 & 32 \\
Au/AuNP/thiol/PEI & Tris-acetate & 8.4 & 750 & 15 & - & 23 \\
Au/thiol/chitosan & Tris & 8.0 & 50 & - & $\sim 0.2$ & 56 \\
\hline
\end{tabular}




\begin{tabular}{ccccccc}
\hline Au/DTSP/AuNP & Tris-acetate & 8.4 & 750 & $1.0 \pm 0.2$ & $32 \pm 2$ & 55 \\
ITO/APTES & Tris-acetate & 8.4 & 750 & $0.45 \pm 0.01$ & $2.2 \pm 0.9$ & 57 \\
\hline
\end{tabular}

ITO: indium tin oxide; DTSP: dithio-bis(N-hydroxysuccinimidyl propionate); APTES: aminopropyltriethoxysilane.
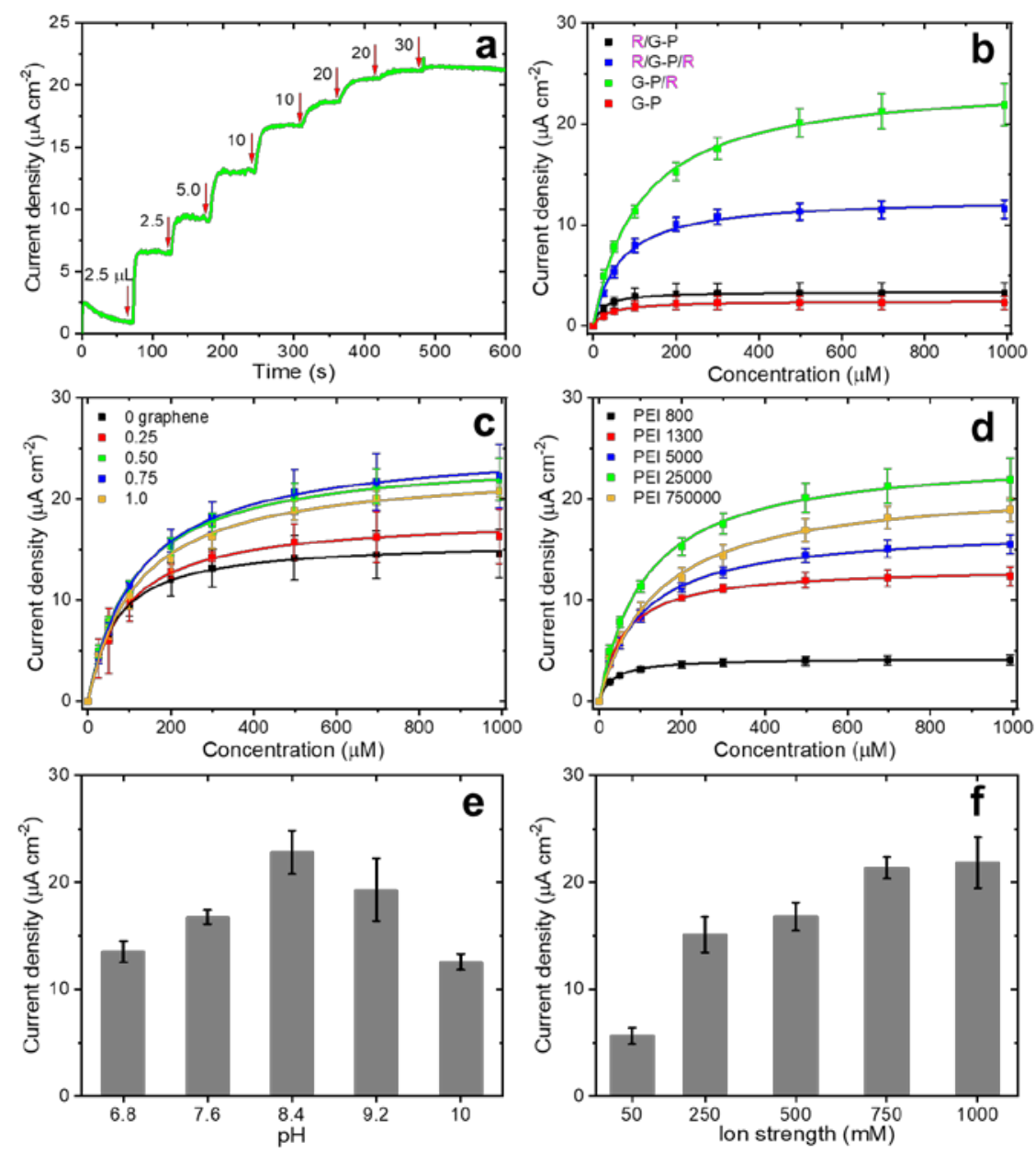

Figure 4. (a) Electrocatalytic responses of $\mathrm{G}-\mathrm{P} / \mathrm{R} / \mathrm{hSO}$ bioelectrodes for increasing concentrations of $\mathrm{Na}_{2} \mathrm{SO}_{3}$ by adding different amounts of $\mathrm{Na}_{2} \mathrm{SO}_{3}$ stock solutions $(150 \mathrm{mM})$ under stirring. The catalytic behavior of various bioelectrodes (b) fabricated by different electroreduction procedures, (c) with different amounts of graphene (RGO), and (d) with different MWs of PEI. The solid lines in (b), (c) and (d) are fitting curves for Michaelis-Menten kinetics. Effects of (e) $\mathrm{pH}$ and (f) ionic strength of buffer on the performance of G-P/R/hSO bioelectrodes towards $1.0 \mathrm{mM} \mathrm{Na} 2 \mathrm{SO}_{3}$ operated at $0 \mathrm{~V}$ vs. Ag/AgCl. All measurements were conducted in oxygen-free Tris-acetate buffer solution under stirring.

Here, graphene is crucial for enhancing the conductivity and surface area of CP. In the absence of graphene (RGO), PEI/R/hSO electrodes show smaller catalytic current compared to G$\mathrm{P} / \mathrm{R} / h S \mathrm{~S}$, Figure 4c. G-P nanomaterials with the concentrations $0.25,0.5$ and $1.0 \mathrm{mg} \mathrm{mL}^{-1}$ graphene and $10 \mathrm{mg} \mathrm{mL}^{-1} \mathrm{PEI}$, were used to optimize the amount of graphene for the $h \mathrm{SO}$ bioelectrodes. The saturation catalytic current increases with increasing graphene 
concentration up to $0.5 \mathrm{mg} \mathrm{mL}^{-1}$, Table S9. $\mathrm{j}_{\mathrm{m}}$ of bioelectrodes with $0.75 \mathrm{mg} \mathrm{mL}^{-1}(25.4 \pm 0.2$ $\left.\mu \mathrm{A} \mathrm{cm}{ }^{-2}\right)$ and $1.0 \mathrm{mg} \mathrm{mL}^{-1}$ graphene $\left(23.2 \pm 0.3 \mu \mathrm{A} \mathrm{cm}{ }^{-2}\right)$ is comparable to that with $0.5 \mathrm{mg}$ $\mathrm{mL}^{-1}$ graphene $\left(24.4 \pm 0.3 \mu \mathrm{A} \mathrm{cm}{ }^{-2}\right) .0 .5 \mathrm{mg} \mathrm{mL}^{-1}$ graphene is thus sufficient and used for the remaining experiments.

G-P nanomaterials were synthesized by partially reducing GO using PEI with MW of 800, 1300, 5000, 25000 or $750000 \mathrm{~g} \mathrm{~mol}^{-1}$ (Figure S5c and 5d). The highest activity was found for the bioelectrodes with the PEI of $25000 \mathrm{~g} \mathrm{~mol}^{-1}$, Figure 4d. PEI with lower MW has been reported to weaken the immobilization strength for nanomaterials and enzyme compared to PEI with a larger $\mathrm{MW},{ }^{58}$ resulting in aggregation of G-P nanomaterials and a lower current response. Further increasing the MW to $750000 \mathrm{~g} \mathrm{~mol}^{-1}$ gives a decreased signal, Figure 4d, which can be explained by the significant drop of the conductivity.

To obtain adsorption behavior of $h \mathrm{SO}$ to G-P/R modified electrode, the catalytic responses after different durations of enzyme incubation were evaluated. A soaring catalytic current is obtained in the first 5 min, indicating quick adsorption of hSO, Figure S16. After 120-min incubation, the catalytic current almost reaches a steady state. $\mathrm{pH}$ and ionic strength of supporting electrolyte were further optimized. The $h S O$ bioelectrode shows the highest activity at $\mathrm{pH} 8.4$ (Figure 4e), close to the optimal $\mathrm{pH}$ (8.5) for $h S \mathrm{O}$ in solution. ${ }^{44}$ The bioelectrocatalysis of hSO on modified CP depends strongly on the ionic strength of the electrolyte, which alters the flexible interaction between the build-in mediator heme $b 5$ domain and the catalytic Mo-containing unit. ${ }^{27}$ The current density increases more strongly with increasing buffer concentration up to $750 \mathrm{mM}$ than that in the concentration range from 750 to $1000 \mathrm{mM}$, Figure 4f. Because high ionic strength facilitates the flexible interaction between the built-in mediator heme $b 5$ domain, the catalytic Mo-containing unit and the electrode is facilitated, enabling higher electrocatalytic response of $h S O$ bioelectrodes. ${ }^{27,} 30,59$ The rest of 
the electrochemical measurements were therefore carried out using a $750 \mathrm{mM} \mathrm{pH} 8.4$ Trisacetate buffer.

Evaluation of Bioelectrodes. The $h S O$ bioelectrodes show a fair stability in freshly changed electrolytes, Figure 5a. After the initial five changes of electrolyte, the catalytic signal shows a rapid decrease, mainly due to enzyme detachment. The loss rate remains at 4 to $5 \%$ of the initial signal at each subsequent electrolyte exchange, implying that the immobilized $h S O$ is gradually inactivated or further detached. In order to discriminate the denaturation from detachment of immobilized $h \mathrm{SO}$ from the electrodes, the catalytic responses on $h \mathrm{SO}$ bioelectrode (G-P/R/hSO) stored in high-humid atmosphere or immersed in Tris-acetate buffer solution (750 mM, pH 8.4) at room temperature for $3 \mathrm{~h}$ were measured. The control is a freshly prepared $h \mathrm{SO}$ bioelectrode. The bioelectrodes stored in high-humid atmosphere and buffer solution decrease by $6 \%$ and $17 \%$ of the original catalytic current, respectively, Figure S17. This suggests that enzyme denaturation (6\%) and enzyme detachment (11\%) constitute the total $17 \%$ of the observed catalytic signal loss.

The stabilized $h S O$ bioelectrode after five electrolyte exchanges was then used to evaluate the DET efficiency. The catalytic current of the $h S \mathrm{O}$ bioelectrodes undergoing mediated electron transfer (MET) was recorded using the mediator TMPD, Figure 5b and Figure S18a. Notably, the catalytic current allows the first estimation of the fraction of immobilized $h S O$ capable of DET. $21 \%$ of the active $h S O$ on the bioelectrode is thus capable of DET, while the rest cannot communicate with the electrode surface directly.

In addition to the electrodes, $\mathrm{O}_{2}$ can also be an external acceptor for the electrons generated from sulfite oxidation at the $h \mathrm{SO}$ co-factor. With the dioxygen reduction by the reduced enzyme, the catalytic current observed by CV scans thus decreases in air compared to $\mathrm{N}_{2}$ atmosphere. ${ }^{32}$ Two successive measurements each in freshly changed degassed electrolyte $(1 \mathrm{st}+\mathrm{D}$ and $2 \mathrm{nd}+\mathrm{D}$ in Figure $5 \mathrm{c})$ were first conducted to ensure that the expected stability of 
the bioelectrode was achieved. It turns out that the rate of catalytic current decrease $(\sim 5 \%$ of the original value) accords with the stability test (Figure 5a). The catalytic activity of the same bioelectrode was then recorded in a non-degassed electrolyte (3rd $+\mathrm{N}$ in Figure $5 \mathrm{c}$ and Figure S18b). Taking into account a 5\% catalytic activity decrease expected from freshly changed degassed electrolyte, an additional $\sim 10 \%$ reduced catalytic current in the non-degassed electrolyte was found, attributed to oxygen reduction by the reduced heme group co-factor. This is comparable to the value ( $4 \%$ ) of $h S O$ on a CdS quantum dot modified ITO surface and much lower than the protein on a AuNP modified Au surface (40\%). ${ }^{32}$
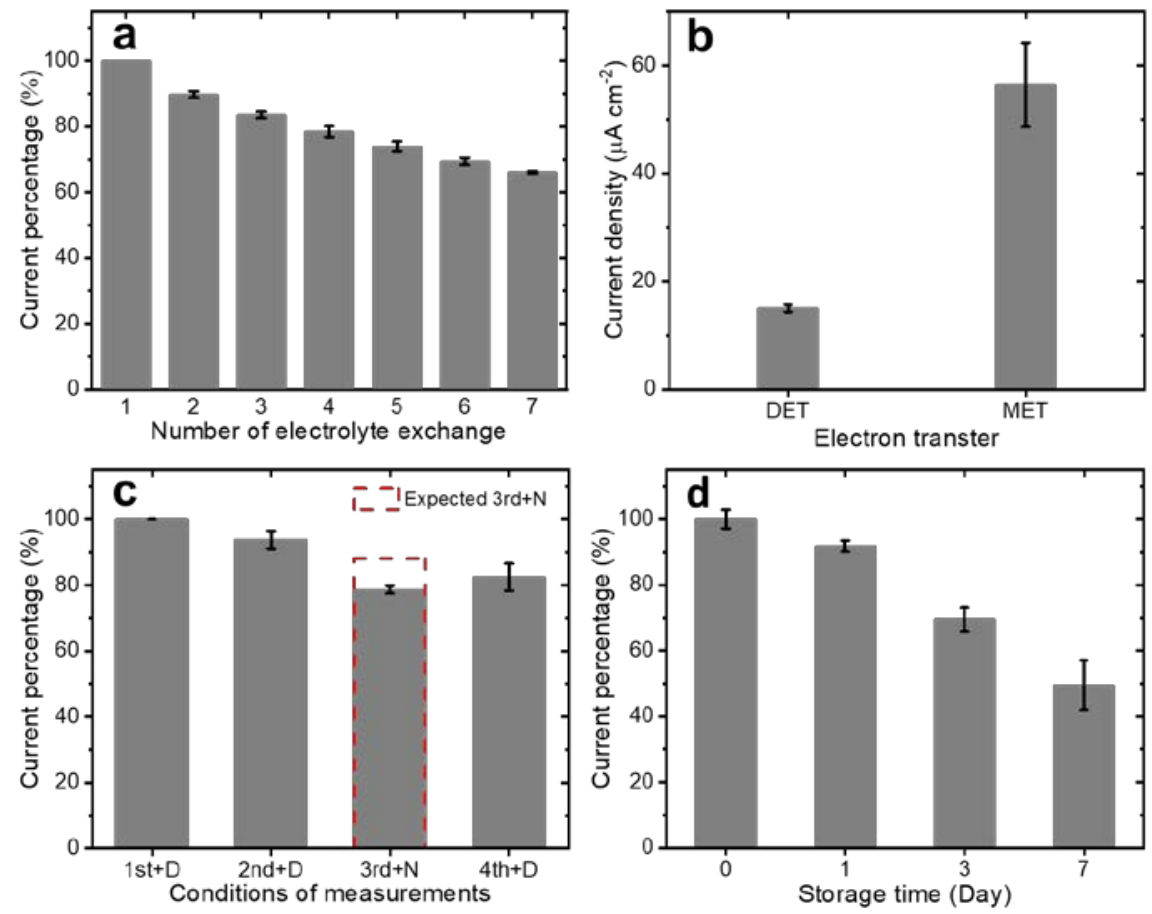

Figure 5. (a) Stability, (b) current density with DET and MET with $0.10 \mathrm{mM}$ mediator TMPD, (c) effects of dioxygen competition and (d) storage lifetime of the G-P/R/hSO bioelectrodes in $1.0 \mathrm{mM} \mathrm{Na} \mathrm{SO}_{3}$ operated at $0 \mathrm{~V}$ vs. Ag/AgCl. Except for the investigation on effects of dioxygen competition, all measurements refer to oxygen-free Tris-acetate buffer $(750 \mathrm{mM}, \mathrm{pH}$ 8.4). D: degassed, N: non-degassed solution

The storage lifetime of the $h S O$ bioelectrode was investigated by storing the electrodes at $4{ }^{\circ} \mathrm{C}$ in a high-humid atmosphere. The bioelectrode activity has reduced by around $10 \%$ and $30 \%$ after one day and three days, respectively, Figure 5d. After one week of storage, the current has dropped by $50 \%$. A decrease of $34 \%$ of the initial response over 180 min was observed 
over the operational lifetime of the bioelectrodes, Figure S19. The loss of activity (50\%) during one-week storage is a consequence of enzyme inactivation and the detachment of immobilized hSO from the electrode surfaces.

Applications of Bioanodes in EBFCs. The $h S O$ bioelectrodes were finally exploited as bioanodes in stacked FCs, coupled with a cathode based on commercial Pt catalysts. The control FC using a G-P/R electrode as the anode and the sulfite/ $\mathrm{O}_{2} \mathrm{EBFC}$ were investigated by recording six consecutive polarization and power curves. The average polarization and power density curves are shown in Figure 6a and b. The EBFCs with an OCV of $0.64 \pm 0.01 \mathrm{~V}$ reach a $\mathrm{P}_{\max }$ of $61 \pm 6 \mu \mathrm{W} \mathrm{cm} \mathrm{c}^{-2}$ (122 $\pm 14 \mathrm{~mW} \mathrm{~m}^{-3}$ for FC full device volumetric power density), while the enzyme-free FCs show an OCV of $0.40 \pm 0.06 \mathrm{~V}$ and a $P_{\max }$ of $4 \pm 2 \mu \mathrm{W} \mathrm{cm}{ }^{-2}(8 \pm 4$ $\mathrm{mW} \mathrm{m}^{-3}$ ). Since $h S O$ catalyzes the sulfite oxidation by reducing the onset potential and increasing the oxidation current, it is reasonable that the presence of $h S \mathrm{O}$ on the anode increases the OCV and thus the FC output power with the efficient commercial cathode. The $\mathrm{P}_{\max }$ decrease is $5 \%$ of the original value each time from the 3rd and 6th measurements, caused by the leakage of loosely bound $h \mathrm{SO}$, as also observed for $h \mathrm{SO}$ bioelectrodes during electrolyte exchange, Figure 5a. On the other hand, the OCV for the EBFCs is almost constant during consecutive measurements, fluctuating only from 0.63 to $0.65 \mathrm{~V}$, Figure 6c. Compared to EBFCs, the performance of the enzyme free control FCs consisting of a G-P/R anode (Figure 6c) clearly degrades faster. The decrease in OCV by $41 \%$ and $\mathrm{P}_{\max }$ by $94 \%$ might be caused by a decrease in the amount of edge plane active sites of graphene sheets due to aggregation during sulfite oxidation. ${ }^{60}$ Since the onset potential for sulfite oxidation by active $h S O$ is stable in EBFCs, the OCV of EBFCs is between 0.63 and $0.65 \mathrm{~V}$. The output $\mathrm{P}_{\max }$ only reduces by $30 \%$ during the six consecutive measurements.

Power outputs from the 3rd and 6th measurements were used to compare the performance of EBFCs at different temperatures, Figure $6 \mathrm{~d}$. The OCV of EBFCs fluctuates from 0.57 to 0.68 
$\mathrm{V}$ as the temperature rises, but without significant average change. This is not surprising, as the stored charges in the capacitive matrix will maintain the OCV at a high level. ${ }^{8}$ However, $\mathrm{P}_{\max }$ increases from $27 \pm 1$ to $61 \pm 6 \mu \mathrm{W} \mathrm{cm}{ }^{-2}\left(64 \pm 2\right.$ to $\left.122 \pm 14 \mathrm{~mW} \mathrm{~m}^{-3}\right)$ when the temperature is increased from 15 to $30^{\circ} \mathrm{C}$, but drops to $42 \pm 4 \mu \mathrm{W} \mathrm{cm}{ }^{-2}\left(84 \pm 8 \mathrm{~mW} \mathrm{~m}^{-3}\right)$ at the further elevated temperature of $40{ }^{\circ} \mathrm{C}$. The EBFCs with an OCV of $0.64 \pm 0.01 \mathrm{~V}$ reaches a $\mathrm{P}_{\max }$ of 61 $\pm 6 \mu \mathrm{W} \mathrm{cm} \mathrm{cm}^{-2}$ at $30{ }^{\circ} \mathrm{C}$, giving a 6.6 -fold better output performance than previously reported sulfite/ $\mathrm{O}_{2}$ EBFCs. ${ }^{23}$ This phenomenon is different from our previously reported non-enzyme FCs which enhance the output performance with elevated temperatures up to $80{ }^{\circ} \mathrm{C} .{ }^{4}$ The temperature-dependent activity of the EBFCs is likely to come from the intrinsic properties of $h S O,{ }^{61}$ as free $h S O$ in solution showed an optimal temperature of $30{ }^{\circ} \mathrm{C}$, consistent with the observation here. The significantly enhanced performance compared to the reported results of sulfite $/ \mathrm{O}_{2}$ EBFCs ${ }^{23}$ can be attributed to the high surface area for $h S O$ loading and faster interfacial and intramolecular electron transfer with concurrent strong electrocatalysis in the designed graphene based matrix.
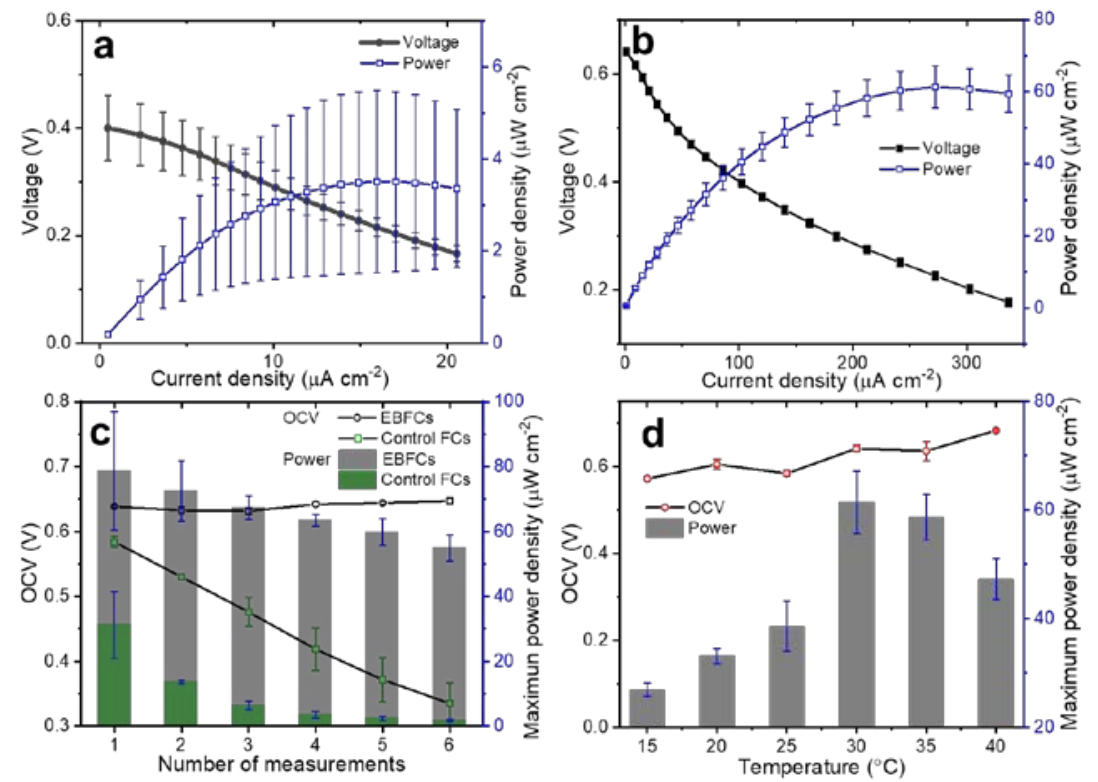

Figure 6. Average polarization and power density curves of (a) control FCs and (b) EBFCs at $30{ }^{\circ} \mathrm{C}$ based on the 3rd to 6th measurements. (c) OCV and maximum power density of EBFCs and control FCs for six consecutive measurements at $30^{\circ} \mathrm{C}$. (d) Performance of EBFCs at different temperatures. All FCs were fed with Tris-acetate buffer (750 mM, pH 8.4) containing 
$25 \mathrm{mM} \mathrm{Na}_{2} \mathrm{SO}_{3}\left(2.0 \mathrm{~mL} \mathrm{~min}^{-1}\right)$ in the presence of dioxygen at the bioanode and dioxygen (100 $\mathrm{mL} \min ^{-1}$ ) at the cathode.

\section{CONCLUSIONS}

We have combined the intriguing properties of $h S O$ with 3D graphene electrodes by fabricating $h S O$ bioanodes via electrostatic adsorption of $h S O$ on the electrode surface modified by the polycation PEI. Electroreduction of the 3D graphene support improves significantly the catalytic performance of the bioelectrodes towards $\mathrm{Na}_{2} \mathrm{SO}_{3}$ oxidation. The optimized saturation oxidation current $\left(24.4 \pm 0.3 \mu \mathrm{A} \mathrm{cm} \mathrm{cm}^{-2}\right)$ is thus around 9 times higher than on bioelectrodes without electroreduction $\left(2.48 \pm 0.08 \mu \mathrm{A} \mathrm{cm} \mathrm{cm}^{-2}\right)$. Electroreduction of $\mathrm{GO}$ on the 3D support can, first increase electronic conductivity of the local microenvironment, and decrease the interfacial electron transfer resistance between the electrode surface and electrolyte, reflecting enhanced contact of hSO with the electrode and therefore increased DET. Secondly, a better immobilization of $h \mathrm{SO}$ via electrostatic interaction can be achieved via electroreduction. The reduction of GO can decrease the amount of oxygenated species on the electrodes and thus weaken the electrostatic repulsion between the negatively charged GO and an enzyme. The designed 3D graphene based electrode could therefore be an excellent support to immobilize also other enzymes with efficient heterogeneous ET in electrocatalytic devices. The developed graphene-based hSO bioanodes combined with commercial Pt catalysts as cathodes were finally used to successfully construct a sulfite/ $\mathrm{O}_{2}$ based EBFC with a $\mathrm{P}_{\max }$ of $61 \pm 6 \mu \mathrm{W} \mathrm{cm}{ }^{-2}$ $\left(122 \pm 14 \mathrm{~mW} \mathrm{~m}^{-3}\right)$ and an OCV of $0.64 \pm 0.01 \mathrm{~V}$ at $30^{\circ} \mathrm{C}$. As a compact power generator or monitor, the stackable EBFC offers great potential for harvesting electrical energy from wastewater, body liquids, foods and beverages containing sulfite.

\section{ASSOCIATED CONTENT}

\section{Supporting Information}

The Supporting Information is available free of charge on the ACS Publications website. 
It includes nineteen supporting figures including preparation of hSO bioelectrodes, EBFC assembly, AFM image, XPS and UV-Vis spectra, enzyme activity and electrochemical data. Nine tables consisting of the summary of relative peak area percentage of carbon bindings, zeta potentials of nanomaterials, key voltammetry parameters of modified electrodes in the presence of $\mathrm{K}_{4}\left[\mathrm{Fe}(\mathrm{CN})_{6}\right]$ or $\left[\mathrm{Ru}\left(\mathrm{NH}_{3}\right)_{6}\right] \mathrm{Cl}_{3}$, EIS fitting parameters, ECSAs of various electrodes, comparison of ECSA and $\mathrm{R}_{\mathrm{ct}}$ of G-P/R electrode with different reduction potential windows, activity assay and enzyme kinetic parameters of various electrodes.

\section{AUTHOR INFORMATION}

\section{Corresponding Author}

E-mail address: jz@kemi.dtu.dk (J.Z.)

\section{Notes}

The authors declare no competing financial interest.

\section{ORCID}

Jing Tang: 0000-0002-8745-9177

Rebecka Maria Larsen Werchmeister: n/a

Loredana Preda: n/a

Wei Huang: 0000-0002-9654-5456

Zhiyong Zheng: 0000-0002-7276-7425

Silke Leimkühler: 0000-0003-3238-2122

Ulla Wollenberger: 0000-0002-7088-8928

Xinxin Xiao: 0000-0002-0240-0038

Christian Engelbrekt: 0000-0003-3679-3666 
Jens Ulstrup: 0000-0002-2601-7906

Jingdong Zhang: 0000-0002-0889-7057

\section{ACKNOWLEDGEMENT}

Financial support from The Danish Council for Independent Research for the YDUN project (DFF 4093-00297) to J. Z., China Scholarship Council (CSC, No. 201706220080 and 201606130019) to W. H. and Z. Z., and H. C. Ørsted COFUND to X. X. is grateful acknowledged. Financial support from the Independent Research Fund Denmark for C. E. (DFF-5054-00107) is acknowledged. U. W., L. P., and S. L. gratefully acknowledge funding by the Deutsche Forschungsgemeinschaft (DFG, German Research Foundation) under Germany’s Excellence Strategy EXC 314/2 (Unicat) and EXC 2008/1 (UniSysCat) 390540038. J. U. acknowledges support from the Russian Science Foundation (17-13-01274).

\section{REFERENCES}

(1) Zhang, W.; Lai, W.; Cao, R., Energy-Related Small Molecule Activation Reactions: Oxygen Reduction and Hydrogen and Oxygen Evolution Reactions Catalyzed by Porphyrinand Corrole-Based Systems. Chem. Rev. 2017, 117, 3717-3797.

(2) Kirubakaran, A.; Jain, S.; Nema, R. K., A Review on Fuel Cell Technologies and Power Electronic Interface. Renew. Sust. Energy Rev. 2009, 13, 2430-2440.

(3) Badwal, S. P. S.; Giddey, S.; Kulkarni, A.; Goel, J.; Basu, S., Direct Ethanol Fuel Cells for Transport and Stationary Applications - A Comprehensive Review. Appl. Energy 2015, 145, 80-103.

(4) Seselj, N.; Engelbrekt, C.; Ding, Y.; Hjuler, H. A.; Ulstrup, J.; Zhang, J., Tailored Electron Transfer Pathways in Aucore/Ptshell-Graphene Nanocatalysts for Fuel Cells. Adv. Energy Mater. 2018, 8, 1702609.

(5) Seselj, N.; Engelbrekt, C.; Zhang, J., Graphene-Supported Platinum Catalysts for Fuel Cells. Sci. Bull. 2015, 60, 864-876.

(6) Giarratano, F.; Arzac, G. M.; Godinho, V.; Hufschmidt, D.; Jiménez de Haro, M. C.; Montes, O.; Fernández, A., Nanoporous Pt-Based Catalysts Prepared by Chemical Dealloying of Magnetron-Sputtered Pt-Cu Thin Films for the Catalytic Combustion of Hydrogen. Appl. Catal. B: Environ. 2018, 235, 168-176.

(7) Zhang, H.; Zhang, L.; Han, Y.; Yu, Y.; Xu, M.; Zhang, X.; Huang, L.; Dong, S., RGO/Au NPs/N-doped CNTs Supported on Nickel Foam as an Anode for Enzymatic Biofuel Cells. Biosens. Bioelectron. 2017, 97, 34-40. 
(8) Xiao, X.; Conghaile, P. O.; Leech, D.; Ludwig, R.; Magner, E., A Symmetric Supercapacitor/Biofuel Cell Hybrid Device Based on Enzyme-Modified Nanoporous Gold: An Autonomous Pulse Generator. Biosens. Bioelectron. 2017, 90, 96-102.

(9) Herkendell, K.; Tel-Vered, R.; Stemmer, A., Switchable Aerobic/Anaerobic MultiSubstrate Biofuel Cell Operating on Anodic and Cathodic Enzymatic Cascade Assemblies. Nanoscale 2017, 9, 14118-14126.

(10) Abreu, C.; Nedellec, Y.; Gross, A. J.; Ondel, O.; Buret, F.; Goff, A. L.; Holzinger, M.; Cosnier, S., Assembly and Stacking of Flow-Through Enzymatic Bioelectrodes for High Power Glucose Fuel Cells. ACS Appl. Mater. Inter. 2017, 9, $23836-23842$.

(11) Huang, X.; Zhang, L.; Zhang, Z.; Guo, S.; Shang, H.; Li, Y.; Liu, J., Wearable Bofuel Cells Based on the Classification of Enzyme for High Power Outputs and Lifetimes. Biosens. Bioelectron. 2018, 124-125, 40-52.

(12) Lang, Q.; Yin, L.; Shi, J.; Li, L.; Xia, L.; Liu, A., Co-Immobilization of Glucoamylase and Glucose Oxidase for Electrochemical Sequential Enzyme Electrode for Starch Biosensor and Biofuel Cell. Biosens. Bioelectron. 2014, 51, 158-163.

(13) Slaughter, G.; Kulkarni, T., A Self-Powered Glucose Biosensing System. Biosens. Bioelectron. 2016, 78, 45-50.

(14) Giroud, F.; Milton, R. D.; Tan, B.-X.; Minteer, S. D., Simplifying Enzymatic Biofuel Cells: Immobilized Naphthoquinone as a Biocathodic Orientational Moiety and Bioanodic Electron Mediator. ACS Cata. 2015, 5, 1240-1244.

(15) So, K.; Kawai, S.; Hamano, Y.; Kitazumi, Y.; Shirai, O.; Hibi, M.; Ogawa, J.; Kano, K., Improvement of a Direct Electron Transfer-Type Fructose/Dioxygen Biofuel Cell with a Substrate-Modified Biocathode. Phys. Chem. Chem. Phys. 2014, 16, 4823-4829.

(16) Jia, W.; Wang, X.; Imani, S.; Bandodkar, A. J.; Ramírez, J.; Mercier, P. P.; Wang, J., Wearable Textile Biofuel Cells for Powering Electronics. J. Mater. Chem. A 2014, 2, 1818418189.

(17) Xiao, X.; Siepenkoetter, T.; Conghaile, P. Ó.; Leech, D.; Magner, E., Nanoporous GoldBased Biofuel Cells on Contact Lenses. ACS Appl. Mater. Inter. 2018, 10, 7107-7116.

(18) Cosnier, S.; Gross, A. J.; Giroud, F.; Holzinger, M., Beyond the Hype Surrounding Biofuel Cells: What's the Future of Enzymatic Fuel Cells? Curr. Opin. Electrochem. 2018, 12, 148155.

(19) Kang, Z.; Jiao, K.; Cheng, J.; Peng, R.; Jiao, S.; Hu, Z., A Novel Three-Dimensional Carbonized PANI1600@CNTs Network for Enhanced Enzymatic Biofuel Cell. Biosens. Bioelectron. 2018, 101, 60-65.

(20) Milton, R. D.; Wu, F.; Lim, K.; Abdellaoui, S.; Hickey, D. P.; Minteer, S. D., Promiscuous Glucose Oxidase: Electrical Energy Conversion of Multiple Polysaccharides Spanning Starch and Dairy Milk. ACS Cata. 2015, 5, 7218-7225.

(21) Temple, C. A.; Graf, T. N.; Rajagopalan, K. V., Optimization of Expression of Human Sulfite Oxidase and Its Molybdenum Domain. Arch. Biochem. Biophys. 2000, 383, 281-287.

(22) Hille, R., The Mononuclear Molybdenum Enzymes. Chem. Rev. 1996, 96, 2757-2816.

(23) Zeng, T.; Pankratov, D.; Falk, M.; Leimkühler, S.; Shleev, S.; Wollenberger, U., Miniature Direct Electron Transfer Based Sulphite/Oxygen Enzymatic Fuel Cells. Biosens. Bioelectron. 2015, 66, 39-42.

(24) Feng, C.; Kedia, R. V.; Hazzard, J. T.; Hurley, J. K.; Tollin, G.; Enemark, J. H., Effect of Solution Viscosity on Intramolecular Electron Transfer in Sulfite Oxidase. Biochemistry 2002, 41, 5816-5821.

(25) Coury, L. A.; Oliver, B. N.; Egekeze, J. O.; Sosnoff, C. S.; Brumfield, J. C.; Buck, R. P.; Murray, R. W., Mediated, Anaerobic Voltammetry of Sulfite Oxidase. Anal. Chem. 1990, 62, 452-458. 
(26) Pacheco, A.; Hazzard, J. T.; Tollin, G.; Enemark, J. H., The pH Dependence of Intramolecular Electron Transfer Rates in Sulfite Oxidase at High and Low Anion Concentrations. J. Biol. Inorg. Chem. 1999, 4, 390-401.

(27) Zeng, T.; Leimkühler, S.; Wollenberger, U.; Fourmond, V., Transient Catalytic Voltammetry of Sulfite Oxidase Reveals Rate Limiting Conformational Changes. J. Am. Chem. Soc. 2017, 139, 11559-11567.

(28) Pundir, C. S.; Rawal, R., Determination of Sulfite with Emphasis on Biosensing Methods: A Review. Anal. Bioanal. Chem. 2013, 405, 3049-3062.

(29) Elliott, S. J.; McElhaney, A. E.; Feng, C.; Enemark, J. H.; Armstrong, F. A., A Voltammetric Study of Interdomain Electron Transfer within Sulfite Oxidase. J. Am. Chem. Soc. 2002, 124, 11612-11613.

(30) Sezer, M.; Spricigo, R.; Utesch, T.; Millo, D.; Leimkühler, S.; Mroginski, M. A.; Wollenberger, U.; Hildebrandt, P.; Weidinger, I. M., Redox Properties and Catalytic Activity of Surface-Bound Human Sulfite Oxidase Studied by a Combined Surface Enhanced Resonance Raman Spectroscopic and Electrochemical Approach. Phys. Chem. Chem. Phys. 2010, 12, 7894-7903.

(31) Frasca, S.; Rojas, O.; Salewski, J.; Neumann, B.; Stiba, K.; Weidinger, I. M.; Tiersch, B.; Leimkühler, S.; Koetz, J.; Wollenberger, U., Human Sulfite Oxidase Electrochemistry on Gold Nanoparticles Modified Electrode. Bioelectrochemistry 2012, 87, 33-41.

(32) Zeng, T.; Leimkühler, S.; Koetz, J.; Wollenberger, U., Effective Electrochemistry of Human Sulfite Oxidase Immobilized on Quantum-Dots-Modified Indium Tin Oxide Electrode. ACS Appl. Mater. Inter. 2015, 7, 21487-21494.

(33) Spricigo, R.; Dronov, R.; Rajagopalan, K. V.; Lisdat, F.; Leimkühler, S.; Scheller, F. W.; Wollenberger, U., Electrocatalytically Functional Multilayer Assembly of Sulfite Oxidase and Cytochrome c. Soft Matter. 2008, 4, 972-978.

(34) Mazurenko, I.; de Poulpiquet, A.; Lojou, E., Recent Developments in High Surface Area Bioelectrodes for Eenzymatic Fuel Cells. Curr. Opin. Electrochem. 2017, 5, 74-84.

(35) Chen, J.; Wang, Y.; Cao, J.; Liu, Y.; Zhou, Y.; Ouyang, J. H.; Jia, D., Facile CoElectrodeposition Method for High-Performance Supercapacitor Based on Reduced Graphene Oxide/Polypyrrole Composite Film. ACS Appl. Mater. Inter. 2017, 9, 19831-19842.

(36) Wang, M.-H.; Ji, B.-W.; Gu, X.-W.; Tian, H.-C.; Kang, X.-Y.; Yang, B.; Wang, X.-L.; Chen, X.; Li, C.-Y.; Liu, J.-Q., Direct Electrodeposition of Graphene Enhanced Conductive Polymer on Microelectrode for Biosensing Application. Biosens. Bioelectron. 2018, 99, 99107.

(37) Kaplan, A.; Yuan, Z.; Benck, J. D.; Govind Rajan, A.; Chu, X. S.; Wang, Q. H.; Strano, M. S., Current and Future Directions in Electron Transfer Chemistry of Graphene. Chem. Soc. Rev. 2017, 46, 4530-4571.

(38) Pei, S.; Cheng, H.-M., The Reduction of Graphene Oxide. Carbon 2012, 50, 3210-3228.

(39) Shao, Y.; Wang, J.; Engelhard, M.; Wang, C.; Lin, Y., Facile and Controllable Electrochemical Reduction of Graphene Oxide and Its Applications. J. Mater. Chem. 2010, 20, 743-748.

(40) Li, Z.; Huang, T.; Gao, W.; Xu, Z.; Chang, D.; Zhang, C.; Gao, C., Hydrothermally Activated Graphene Fiber Fabrics for Textile Electrodes of Supercapacitors. ACS Nano 2017, 11, 11056-11065.

(41) Dong, X.; Wang, X.; Wang, L.; Song, H.; Zhang, H.; Huang, W.; Chen, P., 3D Graphene Foam as a Monolithic and Macroporous Carbon Electrode for Electrochemical Sensing. ACS Appl. Mater. Inter. 2012, 4, 3129-33.

(42) Prasad, K. P.; Chen, Y.; Chen, P., Three-Dimensional Graphene-Carbon Nanotube Hybrid for High-Performance Enzymatic Biofuel Cells. ACS Appl. Mater. Inter. 2014, 6, 3387-93. 
(43) Song, Y.; Chen, C.; Wang, C., Graphene/Enzyme-Encrusted Three-Dimensional Carbon Micropillar Arrays for Mediatorless Micro-Biofuel Cells. Nanoscale 2015, 7, 7084-7090.

(44) Spricigo, R.; Leimkühler, S.; Gorton, L.; Scheller, F. W.; Wollenberger, U., The Electrically Wired Molybdenum Domain of Human Sulfite Oxidase is Bioelectrocatalytically Active. Eur. J. Inorg. Chem. 2015, 2015, 3526-3531.

(45) Spricigo, R.; Richter, C.; Leimkühler, S.; Gorton, L.; Scheller, F. W.; Wollenberger, U., Sulfite Biosensor Based on Osmium Redox Polymer Wired Sulfite Oxidase. Colloid. Surface. A. 2010, 354, 314-319.

(46) Gan, S.; Zhong, L.; Wu, T.; Han, D.; Zhang, J.; Ulstrup, J.; Chi, Q.; Niu, L., Spontaneous and Fast Growth of Large-Area Graphene Nanofilms Facilitated by Oil/Water Interfaces. Adv. Mater. 2012, 24, 3958-3964.

(47) Zhu, Y.; Murali, S.; Stoller, M. D.; Velamakanni, A.; Piner, R. D.; Ruoff, R. S., Microwave Assisted Exfoliation and Reduction of Graphite Oxide for Ultracapacitors. Carbon 2010, 48, 2118-2122.

(48) Zhang, C.; Hao, R.; Liao, H.; Hou, Y., Synthesis of Amino-Functionalized Graphene as Metal-Free Catalyst and Exploration of the Roles of Various Nitrogen States in Oxygen Reduction Reaction. Nano Energy 2013, 2, 88-97.

(49) Huang, W.; Sun, H.; Shangguan, H.; Cao, X.; Xiao, X.; Shen, F.; Mølhave, K.; Ci, L.; Si, P.; Zhang, J., Three-Dimensional Iron Sulfide-Carbon Interlocked Graphene Composites for High-Performance Sodium-Ion Storage. Nanoscale 2018, 10, 7851-7859.

(50) Ramesha, G. K.; Sampath, S., Electrochemical Reduction of Oriented Graphene Oxide Films: An in Situ Raman Spectroelectrochemical Study. J. Phys. Chem. C 2009, 113, 79857989.

(51) Raj, M. A.; John, S. A., Fabrication of Electrochemically Reduced Graphene Oxide Films on Glassy Carbon Electrode by Self-Assembly Method and Their Electrocatalytic Application. J. Phys. Chem. C 2013, 117, 4326-4335.

(52) Wang, Y.; Sauriat-Dorizon, H.; Korri-Youssoufi, H., Direct Electrochemical DNA Biosensor Based on Reduced Graphene Oxide and Metalloporphyrin Nanocomposite. Sensors Actuat. B-Chem. 2017, 251, 40-48.

(53) Pankratov, D.; Pankratova, G.; Dyachkova, T. P.; Falkman, P.; Åkerlund, H.-E.; Toscano, M. D.; Chi, Q.; Gorton, L., Supercapacitive Biosolar Cell Driven by Direct Electron Transfer between Photosynthetic Membranes and CNT Networks with Enhanced Performance. ACS Energy Lett. 2017, 2, 2635-2639.

(54) Pankratova, G.; Pankratov, D.; Hasan, K.; Åkerlund, H.-E.; Albertsson, P.-Å.; Leech, D.; Shleev, S.; Gorton, L., Supercapacitive Photo-Bioanodes and Biosolar Cells: A Novel Approach for Solar Energy Harnessing. Adv. Energy Mater. 2017, 7, 1602285.

(55) Zeng, T.; Frasca, S.; Rumschöttel, J.; Koetz, J.; Leimkühler, S.; Wollenberger, U., Role of Conductive Nanoparticles in the Direct Unmediated Bioelectrocatalysis of Immobilized Sulfite Oxidase. Electroanalysis 2016, 28, 2303-2310.

(56) Kalimuthu, P.; Belaidi, A. A.; Schwarz, G.; Bernhardt, P. V., Chitosan-Promoted Direct Electrochemistry of Human Sulfite Oxidase. J. Phys. Chem. B 2017, 121, 9149-9159.

(57) Saengdee, P.; Promptmas, C.; Zeng, T.; Leimkühler, S.; Wollenberger, U., ThirdGeneration Sulfite Biosensor Based on Sulfite Oxidase Immobilized on Aminopropyltriethoxysilane Modified Indium Tin Oxide. Electroanalysis 2017, 29, 110-115. (58) Mateo, C.; Abian, O.; Fernandez-Lafuente, R.; Guisan, J. M., Reversible Enzyme Immobilization via A Very Strong and Nondistorting Ionic Adsorption on SupportPolyethylenimine Composites. Biotechnol. Bioeng. 2000, 68, 98-105.

(59) Utesch, T.; Sezer, M.; Weidinger, I. M.; Mroginski, M. A., Adsorption of Sulfite Oxidase on Self-Assembled Monolayers from Molecular Dynamics Simulations. Langmuir 2012, 28, 5761-5769. 
(60) Sartori, E. R.; Takeda, H. H.; Fatibello-Filho, O., Glassy Carbon Electrode Modified with Functionalized Carbon Nanotubes within A Poly(allylamine hydrochloride) Film for the Voltammetric Determination of Sulfite in Foods. Electroanalysis 2011, 23, 2526-2533.

(61) Ganai, B.; Masood, A.; Zargar, M.; Syed, M., Kinetics of Sulfite Oxidase Purified from Malva sylvestris. J. Ind. Pollut. Contr. 2006, 22, 77-82. 


\section{Graphical Abstract}

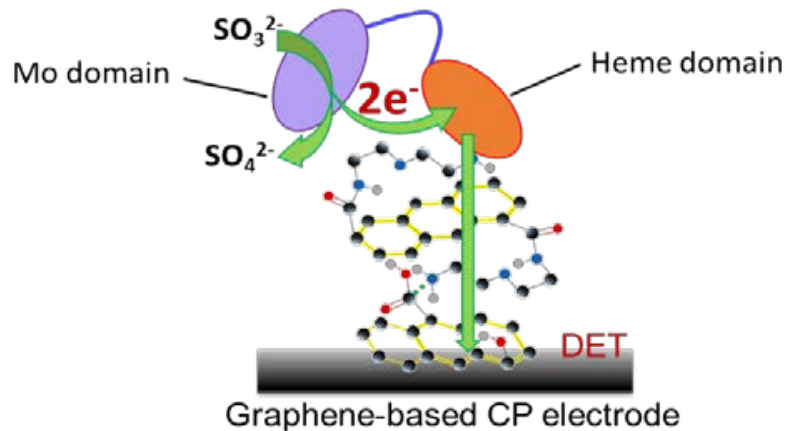

